LAWRENCE LIVERMORE N A T IO N A L LABORATORY
Observations of Ferrite/Austenite Transformations in the Heat Affected Zone of 2205 Duplex Stainless Steel Spot Welds Using Time Resolved X-Ray

Diffraction

T.A. Palmer, J.W. Elmer, S.S. Babu

December 3, 2003

Materials Science and Engineering $A$ 
This document was prepared as an account of work sponsored by an agency of the United States Government. Neither the United States Government nor the University of California nor any of their employees, makes any warranty, express or implied, or assumes any legal liability or responsibility for the accuracy, completeness, or usefulness of any information, apparatus, product, or process disclosed, or represents that its use would not infringe privately owned rights. Reference herein to any specific commercial product, process, or service by trade name, trademark, manufacturer, or otherwise, does not necessarily constitute or imply its endorsement, recommendation, or favoring by the United States Government or the University of California. The views and opinions of authors expressed herein do not necessarily state or reflect those of the United States Government or the University of California, and shall not be used for advertising or product endorsement purposes. 


\title{
Observations of Ferrite/Austenite Transformations in the Heat Affected Zone of 2205 Duplex Stainless Steel Spot Welds Using Time Resolved X-Ray Diffraction
}

\author{
T.A. Palmer ${ }^{*}$ J.W. Elmer, and S.S. Babuł \\ Lawrence Livermore National Laboratory, Livermore, CA 94550, United States \\ † Oak Ridge National Laboratory, Oak Ridge, TN 37831, United States
}

\begin{abstract}
Time Resolved X-Ray Diffraction (TRXRD) measurements are made in the Heat Affected Zone (HAZ) of 2205 Duplex Stainless Steel (DSS) spot welds. Both the $\gamma \rightarrow \delta$ and $\delta \rightarrow \gamma$ transformations are monitored as a function of time during the rapid spot weld heating and cooling cycles. These observations are then correlated with calculated thermal cycles. Where the peak temperatures are highest $\left(\sim 1342^{\circ} \mathrm{C}\right)$, the $\gamma \rightarrow \delta$ transformation proceeds to completion, leaving a ferritic microstructure at the end of heating. With lower peak temperatures, the $\gamma \rightarrow \delta$ transformation proceeds to only partial completion, resulting in a microstructure containing both transformed and untransformed austenite. Further analyses of the individual diffraction patterns show shifts in the peak positions and peak widths as a function of both time and temperature. In addition, these changes in the peak characteristics are correlated with measured changes in the ferrite volume fraction. Such changes in the peak positions and widths during the $\gamma \rightarrow \delta$ transformation provide an indication of changes occurring in each phase. These changes in peak properties can be correlated with the diffusion of nitrogen and other substitutional alloying elements, which are recognized as the primary mechanisms for this transformation. Upon cooling, the $\delta \rightarrow \gamma$ transformation is observed to proceed from both the completely and partially transformed microstructural regions in the TRXRD data. An examination of the resulting microstructures confirms the TRXRD observation as the evidence shows that austenite both nucleates and grows from the ferritic microstructure at locations closest to the fusion zone boundary and grows from untransformed austenite grains at locations further from this boundary.
\end{abstract}

Keywords: Time Resolved X-Ray Diffraction; Duplex Stainless Steels; phase transformations; ferrite; austenite; nitrogen

\footnotetext{
* Corresponding Author. Tel.: 925 423-8468; fax: 925 423-7040; e-mail: palmer18@1lnl.gov
} 


\section{INTRODUCTION}

Spatially Resolved X-Ray Diffraction (SRXRD) using high energy synchrotron radiation is a unique experimental technique developed for the in-situ monitoring of phase transformations during welding. It has been used to study phase transformations in commercially pure titanium, C-Mn steels, and stainless steels. [1-8] Unlike more conventional tools, such as metallography or dilatometry, SRXRD is able to provide a direct, in-situ, real-time monitoring capability for detecting and identifying the phases present at a particular location during welding. The resulting x-ray diffraction patterns can then be analyzed in order to determine the degree to which a phase transformation has progressed.[9-11] Based on these results, the kinetics driving these various phase transformations can be experimentally measured and applied to existing phase transformation models.[12-15]

Ferrite $(\delta) /$ austenite $(\gamma)$ phase transformations in the HAZ of a 2205 Duplex Stainless Steel (DSS) during GTA welding have recently been investigated using SRXRD.[9] A detailed map of the ferrite volume fractions present at locations surrounding the weld pool has been developed. Based on the results in this map, the progress of the $\delta / \gamma$ transformation has been tracked as a function of location. Regions of complete and partial transformation of austenite to ferrite and annealing of the base metal microstructure have been identified on heating. During cooling, austenite reformation of varying extents, depending on the location, has been observed, as well.

Time Resolved X-Ray Diffraction (TRXRD) is used here to further investigate the transformation of austenite to ferrite transformations during both heating and cooling in this alloy by directly monitoring a single distinct location in a spot weld HAZ in real-time. By performing these experiments on a spot weld rather than a moving one, a phase transformation can be tracked over a period of time with a single experiment. The time resolution for TRXRD is also short enough, on the order of 50 to $100 \mathrm{~ms}$, to allow both melting and solidification and solid-state transformations in the HAZ to be directly monitored. This technique has been successfully used to study the solidification behavior of flux cored arc welding electrode materials $[16,17]$ and phase transformations in the fusion zone and HAZ of an AISI 1005 C-Mn steel.[18]

Different phase transformations are expected during both the heating and cooling cycles in this alloy system. During heating, the austenite $(\gamma)$ in the duplex $(\delta / \gamma)$ microstructure decomposes into ferrite $(\delta)$, and the existing and transformed ferrite grains in the microstructure begin to grow. During cooling, the high temperature ferrite phase is back-transformed into austenite. 
A number of researchers have investigated the austenite to ferrite transformation during heating and the austenite reformation transformation during cooling.[19-25] As a result, various analytical models have been developed to explain the mechanisms governing these important transformations. These models are based primarily on the assumption that the diffusion of nitrogen is the controlling mechanism for these transformations.

In this work, TRXRD observations are made at two locations in the HAZ of a 2205 DSS spot weld to monitor the progress of the $\gamma \rightarrow \delta$ transformation under different thermal cycles. Depending on the peak temperatures experienced at each location, the $\gamma \rightarrow \delta$ transformation proceeds to either completion or partial completion. For example, at the location nearest the fusion zone boundary, the $\gamma \rightarrow \delta$ transformation proceeds to completion, resulting in a completely ferritic microstructure by the end of the heating cycle. At a greater distance from the fusion zone, the $\gamma \rightarrow \delta$ transformation does not reach completion, leaving a microstructure containing both transformed and untransformed austenite. During cooling, the $\delta \rightarrow \gamma$ transformation is monitored at each location as austenite both nucleates and grows from the different microstructures created during heating.

Whereas these transformations are expected, the heating and cooling conditions experienced in the spot weld HAZ are much more rapid than those typical under arc welding or materials processing conditions. Therefore, these experiments allow the kinetics of the $\delta / \gamma$ transformation under accelerated heating and cooling rates to be experimentally observed. In addition to the observation of the $\gamma \rightarrow \delta$ and $\delta \rightarrow \gamma$ transformations, measurements of the diffraction peak positions, the full width half maximum (FWHM) values, and integrated intensities in each TRXRD pattern are made. These measurements are then correlated with calculated thermal cycles to help identify the mechanisms governing the $\delta / \gamma$ transformations in this alloy under rapid weld heating and cooling rates.

\section{EXPERIMENTAL PROCEDURE}

\section{Material and Welding Parameters}

Gas tungsten arc (GTA) spot welds have been made on a cylindrical welding sample (10.2 $\mathrm{cm}$ diameter, $8 \mathrm{~cm}$ long) machined from commercial 2205 DSS forged bar stock $(22.43 \mathrm{Cr}-4.88$ Ni-3.13 Mo-1.40 Mn-0.023 C-0.18 N-0.004 S-0.005 O-0.0007H-0.67 Si-0.02 Al-0.03 B-0.08 Co-0.20 Cu-0.03 Nb-0.028 P- $<0.005$ Ti-0.05 V- Bal. Fe). The as-received material has been so- 
lution annealed at $1065^{\circ} \mathrm{C}$ for 2.5 hours followed by water quenching to ambient temperatures to give it nominally equal amounts of ferrite and austenite in the resulting microstructure. This material is the same alloy and heat used in the previously reported SRXRD experiments.[9]

A summary of the spot welding parameters is given in Table 1. To avoid contamination of the weld metal with the external atmosphere, welding is performed in an environmentally sealed chamber filled with helium. The weld is monitored with an infrared camera (FLIR Systems ${ }^{\circledR}$ Model SC1000). High-purity (99.999\%) helium is flowed through the torch and from a helium side blow to provide shielding to the weld pool and to remove soot (condensed metal vapors) from the area being examined with the synchrotron x-rays. Only the arc on time has been varied between the two experiments, in order to change the thermal cycles experienced in the HAZ. The weld pool diameters varied from 10 to $11 \mathrm{~mm}$, and the measured depth of the weld cross section is approximately $1.7 \mathrm{~mm}$ for an arc on time of $20 \mathrm{sec}$. More detailed descriptions of the welding set-up are given in previous publications.[1-10]

Quantitative metallographic (QTM) measurements have been made on samples taken from an as-received 2205 DSS forged bar. Etching of these samples has been performed using an electrolytic $\mathrm{NaOH}$ etch described in ASTM standard A 923-98.[26] Measurements of the austenite area fraction have been made at several locations along orientations both parallel and perpendicular to the extrusion direction using Image Pro Plus ${ }^{\circledR}$ Version 4.0. Only ferrite and austenite are assumed to exist in the various micrographs analyzed here. Results of these measurements are shown in Table 2. There are slight differences between these results and those previously reported for this same heat of material,[9] in part, because the previous measurements were made over only a single orientation and at fewer locations.

The DSS base metal has been analyzed using electron microscopy in order to determine the concentrations of each of the alloying elements. A JEOL JXA-8200 electron microprobe using a $15 \mathrm{keV}, 20 \mathrm{nA}$ electron beam focused to a diameter of $\sim 0.1 \mu \mathrm{m}$ was used to perform this analysis. X-ray intensities are converted to element concentrations (wt. \%) using a CITZAF algorithm, based on analyses of the following standards: $\mathrm{Si}, \mathrm{Fe}, \mathrm{Ni}, \mathrm{Cr}, \mathrm{Mo}$ - pure metals, $\mathrm{C}$ - graphite, $\mathrm{N}-\mathrm{B}_{4} \mathrm{~N}$, and $\mathrm{Mn}-$ spessartine, which is a Mn-bearing silicate mineral. Data have been collected along a $1 \mathrm{~mm}$ traverse using a $1 \mu \mathrm{m}$ spacing between points. 


\section{TRXRD Experiments}

The TRXRD experiments are performed on the 31-pole wiggler beam line (BL 10-2)[27] at the Stanford Synchrotron Radiation Laboratory (SSRL) on the Stanford Positron-Electron Asymmetric Ring (SPEAR). A schematic drawing of the basic features in the TRXRD experimental set-up is shown in Figure 1. In this setup, the focused synchrotron beam which emerges from a toroidal mirror (1 mm high x $2 \mathrm{~mm}$ wide) passes through a double Si(111) crystal monochromator and a $540 \mu \mathrm{m}$ tungsten pinhole to render a sub-millimeter beam on the sample at an incident angle of approximately $25^{\circ}$. A photon energy of $12.0 \mathrm{keV}(\lambda=0.1033 \mathrm{~nm})$ has been chosen to maximize the number of observable diffraction peaks and to ensure that the photon energy is high enough above the Fe K-edge $(7.112 \mathrm{keV})$ and the Ni K-edge $(8.332 \mathrm{keV})$ to minimize the K-fluorescence contribution from the sample.

TRXRD patterns are recorded using a $50 \mathrm{~mm}$ long, 2048 element position sensitive Si photodiode array detector. The detector array is Peltier-cooled and is placed approximately $10 \mathrm{~cm}$ from the x-ray incident point on the sample in order to cover a $2 \theta$ range from approximately $25^{\circ}$ to $52^{\circ}$, where $\theta$ is the Bragg angle. Within this $2 \theta$ range, there are three peaks associated with the bcc $(\delta-\mathrm{Fe})$ and three peaks associated with the fcc $(\gamma-\mathrm{Fe})$ phases.[28] The calibration of the photodiode array numbers to $2 \theta$ values is performed using a $\mathrm{Nb}$ foil.[9-10] During spot welding, 600 measurements are taken at a fixed time interval of $100 \mathrm{~ms}$. Transformations taking place at a given beam location are then tracked as a function of time. Detailed information for the two locations is given in Table 3.

The accuracy of the x-ray beam location with respect to the spot weld is affected by errors in the placement of the beam with respect to the welding electrode, the side-to-side motion of the weld pool, and changes in the size of the weld pool. The adjustment of the electrode position to the desired starting position for the TRXRD measurements contributes an uncertainty of \pm 0.25 $\mathrm{mm}$ in the beam location. Real-time weld monitoring with an IR camera indicates that the weld bead displays a side-to-side motion. An additional uncertainty of $\pm 0.25 \mathrm{~mm}$ is estimated in the actual location of the weld fusion line caused by the side-to-side motion of the weld pool, which is decreased by the use of a pulsed current in the welding process. These sources of error result in an uncertainty of approximately $\pm 0.5 \mathrm{~mm}$ in the position of a measurement. Further details regarding the general experimental set-up are described elsewhere.[1-10] 


\section{Diffraction Peak Analysis}

Quantitative analyses are performed on the individual Bragg peaks in each TRXRD pattern to measure their respective integrated intensity, full width at half maximum (FWHM), and $2 \theta$ values. In order to measure these values, the experimental peak is fitted with a sum of one or more Gaussian peak profile functions and a linear background and then measured using an automated curve-fitting routine developed in Igor Pro ${ }^{\circledR}$, Version 4.0. This technique is similar to one used to analyze SRXRD results.[9]

Additional analysis is performed on the diffraction patterns to estimate the volume fractions and calculate the lattice parameters for ferrite and austenite from the $2 \theta$ values of the peaks present in each diffraction pattern. In order to calculate the lattice parameter of each phase as a function of time, the $\mathrm{d}$-spacing is calculated from the measured $2 \theta$ value for each peak present in the individual diffraction patterns using Bragg's Law (Eq. 1). The d-spacing is then converted to the lattice parameter using the relation in Eq. 2, which is valid for cubic systems:[29]

$$
\begin{aligned}
& \lambda=2 \mathrm{~d} \sin \theta \\
& \mathrm{a}=\mathrm{d} \sqrt{\mathrm{h}^{2}+\mathrm{k}^{2}+\mathrm{l}^{2}}
\end{aligned}
$$

where $\lambda$ is the $\mathrm{x}$-ray wavelength $(0.1033 \mathrm{~nm}), \mathrm{d}$ is the inter-planar spacing $(\mathrm{nm}), \mathrm{a}$ is the lattice parameter (nm), and hkl are the Miller indices for each peak. The lattice parameter reported for each phase is the average of the values calculated for that phase from each of the peaks present in the specific diffraction pattern. Since the lattice parameters and $2 \theta$ values are inversely proportional, the resulting ferrite and austenite lattice parameters display shifts in a direction opposite to that observed in the $2 \theta$ values.

The $\delta / \gamma$ phase balance is semi-quantitatively determined by measuring the respective integrated peak intensities for each phase and then calculating the ratio between these values and the sum of all of the integrated peak intensities in the diffraction pattern. Since both phases are present at room temperature in the starting material, the intensity fractions are then normalized with respect to the base metal volume fractions measured using quantitative metallography. It is necessary to normalize the measured intensity fractions because of differences between the base metal $\delta / \gamma$ phase balance measured metallographically $(54 / 46)$ and the base metal diffraction in- 
tensity fraction (62/38). The intensity fractions measured in each diffraction pattern are normalized with the quantitative metallography measurements using the following relations:

$$
\begin{aligned}
& \delta=\mathrm{C}_{\delta}\left(\delta_{\text {TRXRD }}\right) \\
& \gamma=1-\delta
\end{aligned}
$$

where $\delta$ is the normalized volume fraction of ferrite, $\mathrm{C}_{\delta}\left(=\delta_{\mathrm{MET}} / \delta_{\mathrm{TRXRD}}\right)$ is the normalization constant, $\delta_{\text {TRXRD }}$ is the fraction of $\delta$ measured in the TRXRD patterns, and $\delta_{\text {MET }}$ is the volume fractions of $\delta$ measured using quantitative metallography. A summary of the base metal intensity and volume fractions is presented in Table 2 .

\section{Calculated Thermal Cycles}

Because of the many difficulties encountered in the accurate measurement of temperatures in the HAZ of spot weld, a transient numerical heat transfer and fluid flow model, developed by previous researchers,[30] is used to calculate the weld thermal cycles. In this model, the governing equations are solved in a three dimensional Cartesian coordinate system. This and previous models have been extensively tested on this material system [9] and other materials systems, including C-Mn steels [12,13,31] and titanium.[5] The material parameters shown in Table 4 are used in the calculations, and Figures $2(\mathrm{a} \& \mathrm{~b})$ show the calculated thermal and fluid velocity profiles on the top surface and along the cross section, respectively. A comparison between the calculated spot weld cross section and a typical weld cross section shows good agreement between the calculated and experimental results. For example, the measured diameter of the top surface $(10.48 \pm 0.51 \mathrm{~mm})$ of a typical spot weld compares well with the value calculated using the thermo-fluids model $(10.60 \mathrm{~mm})$. The measured cross section depth of the spot weld $(1.72 \mathrm{~mm})$ also compares favorably with the calculated value $(1.92 \mathrm{~mm})$.

Based on these calculations, the thermal cycles experienced at the spot weld center and at the two monitoring locations are shown in Figure 3 with arc on times of 17 and 20 seconds, respectively, for Locations A and B. A computation time of 60 seconds is used so that the cooling cycle can be monitored for 40 seconds after the arc is extinguished. This time frame matches that used in the TRXRD observations, and allows the temperature calculated at a given time to be correlated with the matching TRXRD measurement. The initial heating and cooling rates, calculated immediately after the initiation and extinguishing of the arc, are extremely rapid, especially 
at locations close to the heat source. After the initially rapid heating and cooling, the heating and cooling rates slow considerably. Distinct differences in the calculated rates arise at further distances from the heat source, indicating that differences in the phase transformation behavior are expected at these locations.

\section{RESULTS}

\section{Location A}

This first TRXRD run is performed at an HAZ location approximately $0.2 \mathrm{~mm}$ from the fusion zone boundary of a spot weld made with an arc-on time of 17 seconds. Figure 4 shows a pseudo-color plot of the $2 \theta$ values vs. time, with the intensities of each peak color-coded. The lighter coloring in each peak trace represents a higher intensity for that peak, while the darker coloring represents a lower intensity, which extends to the background shading. In this plot, ferrite peaks are present throughout the TRXRD run, while the austenite peaks disappear during the heating cycle (12.8 seconds) and reappear during cooling after the arc has been extinguished (22.4 seconds). The disappearance of the austenite peaks during heating represents the completion of the $\gamma \rightarrow \delta$ transformation. Their reappearance during cooling represents the back transformation $(\delta \rightarrow \gamma)$ of the completely ferritic microstructure to austenite.

During the initial stages of heating, the bcc(110) peaks begin to show a speckled appearance. Speckling results from the loss of the polycrystalline behavior of the diffraction pattern as the Debye rings begin changing to Laue spots.[29] Since a linear detector array is used in these experiments, the transition from Debye rings to Laue spots causes peaks in the $2 \theta$ window being monitored to shift as the grains grow during heating, making it difficult to quantitatively analyze the patterns in these regions.

The measured ferrite volume fractions along with the corresponding thermal cycle calculated at this location are plotted as a function of time in Figure 5. During the initial portion of the heating cycle, the speckling in the diffraction patterns produces scatter in the measured ferrite volume fractions. With continued heating, the ferrite volume fraction increases rapidly to values near $100 \%$, where it remains for several more seconds before the austenite disappears. Only ferrite is present during the remainder of the heating cycle and for several seconds after the extinguishing of the arc. The ferrite volume fraction then begins to decrease, representing the initiation of austenite reformation, and slowly decreases over the remainder of the TRXRD run. 
In addition, the positions and widths of the peaks present in each diffraction pattern have been measured. Shifts in the ferrite and austenite lattice parameters are plotted as a function of time over the course of the TRXRD run in Figure 6(a). The austenite phase displays a greater expansion and contraction, owing, in part, to its higher thermal expansion coefficient. At the conclusion of the TRXRD run, the austenite lattice parameter is slightly higher and the ferrite lattice parameter slightly lower than the values measured in the base material prior to welding.

The lattice parameters display significant shifts from the original base metal values over the course of the TRXRD run as a result of the rapid heating and cooling cycles prevalent during spot welding. These thermal excursions cause an expansion/contraction of the lattice structure, stress relief of the phases during heating, and diffusion of interstitial and substitutional alloying elements. In this case, the temperature effects dominate in producing the most obvious shifts in both the lattice parameters. However, additional changes in the ferrite and austenite lattice parameters are observed at times of approximately eight seconds. Rather than continue the expansion in the lattice parameters expected during heating, the ferrite and austenite lattice parameters display a simultaneous contraction, ending when the austenite peaks disappear. These unexpected shifts coincide with the end of the $\gamma \rightarrow \delta$ transformation.

The measured peak widths (FWHM values) for the fcc(111) and bcc(110) peaks are plotted as a function of time in Figure 6(b). In general, the peak widths decrease during heating and remain constant or slightly broaden during cooling. At a time of approximately 4 seconds, corresponding to the beginning of the $\gamma \rightarrow \delta$ transformation, there is a rapid increase in the FWHM values for the fcc(111) peak, which is followed by a rapid decline in the peak widths leading to their eventual disappearance. During cooling, the fcc(111) peak, which reappears after the arc is extinguished, displays a much wider variation in its FWHM values than the bcc(110) peaks over the course of the cooling cycle.

\section{$\underline{\text { Location B }}$}

A plot of peak intensities measured as a function of time over the course of the TRXRD run made at Location B is given in Figure 7. Ferrite and austenite peaks are present throughout, because the duplex microstructure is never completely transformed to ferrite during heating. In addition, changes in the peak intensities are evident during both heating and cooling, indicating that phase transformations are taking place. There is some initial speckling in the bcc(110) peaks 
at times immediately prior to and following the extinguishing of the arc. As cooling continues, though, this speckling diminishes, and the bcc(110) peak intensity remains relatively constant for the remainder of the TRXRD run.

The ferrite volume fractions at each time step have been calculated and are shown in Figure 8 along with the corresponding calculated thermal cycle. The ferrite volume fraction increases during the heating cycle, resulting in a final microstructure with a higher ferrite volume fraction than that observed prior to spot welding but not fully transformed to ferrite. No ferrite volume fraction measurements are shown in the region where speckling has been observed because of the unreliability of the data. Instead, a dotted line represents the general increase expected in the ferrite volume fractions, culminating in the higher ferrite volume fractions measured after the speckling of the diffraction patterns ceases. A slight decrease in the ferrite volume fraction is observed as the material cools and a portion of the high temperature ferrite is transformed to austenite.

The ferrite and austenite lattice parameters are plotted as a function of time in Figure 9(a). In this plot, the same trends observed at Location A are also seen here. For example, during heating, the ferrite and austenite lattice parameters expand, while both values display the opposite effect, contraction, during cooling. The FWHM values of the fcc(111) and bcc(110) peaks are plotted in Figure 9(b). Both peaks display similar decreases in value throughout the heating cycle. Once the speckling of the bcc(110) peaks begins, their FWHM values display significant scatter, while those for the austenite peaks display no such scatter and continue to narrow. Prior to the extinguishing of the arc, the fcc(111) peaks broaden for several seconds before reaching a constant level once cooling begins. As the cooling cycle continues, the speckling of the bcc(110) peaks disappears, and these peaks become significantly narrower than the fcc(111) peaks.

\section{DISCUSSION}

The $\gamma \rightarrow \delta$ transformation during heating in duplex stainless steels occurs via diffusion of both substitutional and interstitial alloying elements. Of these alloying elements, the diffusion of nitrogen is believed to control this transformation on heating.[19,20] The diffusion of nitrogen and other alloying elements is affected by the thermal cycles experienced at that location and the partitioning of alloying elements between the ferrite and austenite grains. Figures $10(a \& b)$ show typical compositional profiles in the region of a $\delta / \gamma$ interface taken from an electron microprobe 
trace made on a portion of the 2205 DSS base metal used in this study. Both the substitutional alloying elements (Cr, Ni, Mo), shown in Figure 10(a), and the primary interstitial element (N), shown in Figure 10(b), display this distinct partitioning between the individual grains of each phase. As expected, the $\mathrm{Ni}$ and $\mathrm{N}$ are partitioned preferentially to the austenite phase, while the $\mathrm{Cr}$ and Mo are partitioned to the ferrite phase. The distribution of these alloying elements, along with the grain size typical of each phase are both important factors in calculating the kinetics of the observed phase transformations.

Figure 11 shows the results of equilibrium thermodynamic calculations for ferrite, austenite, and liquid in this particular 2205 DSS alloy. The base metal ferrite and austenite fractions measured using quantitative metallography. These non-equilibrium base metal ferrite and austenite fractions at room temperature result from the quenching of the forged bar from a temperature of $1065^{\circ} \mathrm{C}$ during processing. According to the equilibrium thermodynamic calculations, the $\gamma \rightarrow \delta$ transformation will occur during heating beginning at temperatures above $855^{\circ} \mathrm{C}$. Thus, there is a driving force for the $\delta \rightarrow \gamma$ transformation at temperatures below $855^{\circ} \mathrm{C}$.

Included in the data obtained using TRXRD is a wealth of information concerning the characteristics of each phase at each time increment. For example, the peak position contains information about the level of strain, temperature, and composition. The peak widths contain information about the micro-strain state of each phase. When compared with the times and temperatures over which these transformations are observed, potential mechanisms driving the observed phase transformations can be identified.

\section{$\chi \rightarrow \delta$ Transformation}

At each location, the $\gamma \rightarrow \delta$ transformation during heating is observed. The extent to which the this transformation is allowed to proceed differs as a result of the different thermal cycles experienced at each location. A summary of the times, temperatures, and peak characteristics observed at Locations $\mathrm{A}$ and $\mathrm{B}$ is shown in Tables 5 and 6, respectively. In each table, the characteristics of each phase at the initiation and completion of this transformation and the $\delta \rightarrow \gamma$ transformation are noted. For example, the higher temperatures experienced at Location A allow the $\gamma \rightarrow \delta$ transformation to reach completion. Whereas at Location B, the lower temperatures experienced here do not allow this transformation to proceed to completion, leaving a microstructure containing untransformed austenite at the conclusion of the heating cycle. 
In Figure 5, the initiation of the $\gamma \rightarrow \delta$ transformation at Location A, as indicated by a rapid increase in the ferrite volume fraction, is observed at a temperature of approximately $1068^{\circ} \mathrm{C}$ and a time of 5.2 seconds. At the times leading up to the initiation of the transformation, the calculated heating rate reaches values in excess of $200^{\circ} \mathrm{C} / \mathrm{sec}$. Once initiated, the transformation proceeds rapidly, with only very small amounts of austenite detected in the diffraction patterns after a period of approximately three seconds. Small amounts of austenite persist for several more seconds before completely disappearing (12.8 seconds) at a calculated temperature of approximately $1342^{\circ} \mathrm{C}$, whereas the calculated $\delta / \gamma$ solvus temperature for this alloy is $1316^{\circ} \mathrm{C}$. A small amount of superheating $\left(28^{\circ} \mathrm{C}\right)$ is therefore necessary in order to complete the $\gamma \rightarrow \delta$ transformation.[9]

At Location B, the $\gamma \rightarrow \delta$ transformation is initiated at a temperature of approximately $725^{\circ} \mathrm{C}$ and a time of 6.3 seconds. Whereas the time at which the transformation is initiated occurs a short time after that observed at Location A, the temperature is lower. This lower temperature may be the result of a lower heating rate $\left(149^{\circ} \mathrm{C} / \mathrm{sec}\right)$ leading up to the initiation of the transformation. Once initiated, though, the transformation proceeds at a slower rate than that observed at Location A. Since a peak temperature of only $1075^{\circ} \mathrm{C}$ is reached at this location, the $\gamma \rightarrow \delta$ transformation does not reach completion.

A comparison between the results obtained for the $\gamma \rightarrow \delta$ transformation at each location shows a number of similarities. At each location, the transformation is characterized by an initial sluggishness, in which the increase in ferrite volume fraction is rather slow. This condition is particularly well illustrated at Location B. After this initial sluggishness, the ferrite volume fractions show a rapid increase, which coincides with the observed changes in the measured peak widths (Figures 6(b) and 9(b)). These regions thus bear the most scrutiny and provide the best indication for determining the mechanisms responsible for the transformation.

Changes in ferrite and austenite peak positions and widths at times leading up to and during the $\gamma \rightarrow \delta$ transformation provide additional insight into the mechanisms governing this transformation. These changes, and how they correspond with the transformation when it proceeds to completion, are shown in Figures 6(a) and 6(b). The combination of the changes in peak widths and peak positions provides an indication for the mechanism of the $\gamma \rightarrow \delta$ transformation from initiation to completion. At times corresponding with the observed changes in the fcc(111) peak width, the $\gamma \rightarrow \delta$ transformation is being initiated and progresses rapidly for a short period of time 
until little austenite is detected. These initial stages of the observed $\gamma \rightarrow \delta$ transformation are most likely the result of nitrogen diffusion. At the latter stages of the observed transformation, where the measured ferrite volume fraction is nearly $100 \%$, a contraction in lattice parameters for both phases is detected. Over the course of this contraction, the rate of increase in the ferrite volume fraction is very low, and austenite is detected for nearly 4 more seconds. The contraction in lattice parameters occurs at higher temperatures and most likely corresponds with the diffusion of substitutional alloying elements, such as Ni, Cr, and Mo. At Location B, similar behavior is observed in the lattice parameters and peak widths (Figures 9(a) and 9(b)). In particular, the fcc(111) peak broadens during heating (Figure 9(b)), indicating that changes are occurring in the micro-strain state of the austenite grains. Unlike the conditions at Location A, though, this peak broadening occurs well after the initiation of the transformation is identified.

Taken together, these results show that the behaviors of the ferrite and austenite phases vary during the $\gamma \rightarrow \delta$ transformation. In general, the changes in the lattice parameters and FWHM values for each phase indicate that changes are occurring in the stress states and micro-strain conditions in each phase as the transformation proceeds. Such changes are most likely indications of diffusion of alloying elements, in particular, nitrogen, occurring between the ferrite and austenite grains. The calculated temperatures corresponding with these observed changes in the peak characteristics and the onset of the $\gamma \rightarrow \delta$ transformation are high enough $\left(>1000^{\circ} \mathrm{C}\right)$ to drive the diffusion of this interstitial alloying element and possibly that for other alloying elements.

With continued heating, ferrite grain growth continues in the ferritic microstructure formed after the $\gamma \rightarrow \delta$ transformation has reached completion. At these times, the bcc(110) peak intensity rapidly increases. Over this same time frame, the peak positions and widths of the ferrite phase remain unchanged. Such uniformity is an indication that there is little to no change in the composition or stress state of the ferrite grains, even though the heating cycle is continuing. With continued heating, ferrite grain growth proceeds, since ferrite is the only remaining phase in the microstructure. In fact, ferrite grain growth is observed metallographically as well at locations adjacent to the fusion zone. A typical example is shown in Figure 12(a).

\section{Austenite Reformation on Cooling}

As the arc is extinguished and the cooling cycle begins, the $\gamma \rightarrow \delta$ transformation comes to an end. At each location, the ferrite volume fractions decrease with cooling, as shown in Figures 5 
and 8 , indicating that austenite reformation is occurring. The different characteristics of austenite reformation at each location result from differences in the beginning microstructure and the thermal cycles experienced at each location. For example, the microstructure at Location A at the beginning of the cooling cycle is completely ferritic, while that at Location B contains both untransformed and partially transformed austenite and ferrite. Unlike the conditions on heating, the cooling cycles experienced at these two locations are rather similar, as shown in Figure 3.

As austenite is formed from the single phase ferritic microstructure at Location A, the measured austenite lattice parameters and $f c c(111)$ peak widths display significant scattering, as shown in Figures 6(a) and 6(b), respectively. This scatter is an indication of the small austenite grain size, resulting from the nucleation of the austenite grains from a completely ferritic microstructure. Once nucleated these grains begin to grow, but the rapid cooling $\left(\sim 217^{\circ} \mathrm{C} / \mathrm{sec}\right)$ experienced at this location limits their growth. On the other hand, the back transformation of austenite from a partially transformed microstructure at Location B is dominated by growth from existing austenite grains. As a result, the volume fractions and peak widths show little scatter.

The rapid cooling experienced at each location immediately after the arc is extinguished appears to delay the onset of austenite reformation at each location. Calculated temperatures fall to levels between only 300 to $400^{\circ} \mathrm{C}$ under cooling rates of approximately $225^{\circ} \mathrm{C} / \mathrm{sec}$ before the onset of the austenite back transformation is detected. In addition, these rapid cooling rates hinder the back-transformation to austenite from proceeding to the extent normally observed in moving welds. The resulting microstructures confirm these results. Figures 12(a-c) show optical micrographs of the variations in the microstructures across the HAZ from the fusion zone to the base metal. Variations in the austenite morphology are visible across all of these regions and provide an indication of the differences in the degree to which the austenite reformation process has proceeded at the different locations.

Typical microstructures present in the vicinity of Locations A and B are shown in Figures 13(a\&b), respectively. In these figures, there are significant differences in the morphology of the austenite grains at each location. For example, at Location A, the austenite grains appear primarily along grain boundaries and as small grains in the interior of austenite grains. At the grain boundaries, the austenite grains take on a Widmänstatten appearance. In addition, there are denuded zones present around these austenite grains, indicating that diffusion is occurring, even under these rapid cooling rates. 
In the vicinity of Location B, the austenite grains take on a much different appearance, as shown in Figure 13(b). Since the austenite in the original duplex microstructure has not completely decomposed to ferrite during heating, the newly transformed austenite can grow from the interface between the untransformed austenite and ferrite. As a result, the untransformed austenite grains no longer display the smooth interfaces with the ferritic matrix observed in the base metal microstructure. Rather, the edges of the austenite grains take on a jagged appearance as austenite grains grow from the larger untransformed grains. There is also evidence of Widmänstatten formation of austenite in these locations.

In addition to the changes in the austenite morphologies present in the HAZ, the appearance of another prominent precipitate in the microstructure is observed. These precipitates appear as dark secondary particles in the ferrite grains. With increasing distance from the fusion zone boundary, these precipitates decrease in volume fraction and eventually disappear at a distance of approximately $2 \mathrm{~mm}$ from the fusion zone boundary. Based on previous research in these alloys,[33-37] these precipitates are believed to $\mathrm{be}^{\mathrm{Cr}} \mathrm{r}_{2} \mathrm{~N}$, which form at temperatures between $700^{\circ} \mathrm{C}$ and $900^{\circ} \mathrm{C}$. The formation of these $\mathrm{Cr}_{2} \mathrm{~N}$ precipitates within the ferrite grains is aided by this rapid cooling, which creates a supersaturated solid solution, primarily of $\mathrm{Cr}$ and $\mathrm{N}$, in the interior of the ferrite grains. As the distance from the spot weld is increased, these precipitates eventually disappear.

\section{SUMMARY AND CONCLUSIONS}

The $\gamma \rightarrow \delta$ and $\delta \rightarrow \gamma$ transformations have been monitored as a function of time at two locations in the HAZ of 2205 DSS spot welds using TRXRD techniques. At each location, the $\gamma \rightarrow \delta$ transformation is observed on heating and the $\delta \rightarrow \gamma$ transformation is observed on cooling. In order to quantify these observations, a semi-quantitative analysis, based on the integrated intensity of the peaks in each diffraction pattern, has been performed to determine the variations in the ferrite volume fraction as a function of time. In addition, the diffraction peak positions and widths have been measured and changes in these values tracked over the course of the TRXRD run. Correlations are also made between these measurements and the calculated thermal cycles experienced at these monitoring locations. A summary of the primary conclusions of this work is given below: 


\section{$\underset{\gamma \rightarrow \delta \text { Transformation (Heating) }}{ }$}

- The $\gamma \rightarrow \delta$ transformation on heating has been observed to proceed to completion and to partial completion at different locations in the spot weld HAZ. The degree of completion of this transformation depends on the thermal cycles experienced at each location.

- Broadening of the austenite peak widths during heating coincides with the beginning of the $\gamma \rightarrow \delta$ transformation at temperatures between $900^{\circ} \mathrm{C}$ and $1000^{\circ} \mathrm{C}$. Such changes in the peak characteristics are indications that diffusion, most likely of nitrogen, is changing the chemical composition of the austenite phase at the onset of the $\gamma \rightarrow \delta$ transformation.

- Both the ferrite and austenite lattice parameters contract at times following the broadening of the austenite peak widths when the $\gamma \rightarrow \delta$ transformation is allowed to proceed to completion. The contraction in the two phases occurs at a temperature of approximately $1200^{\circ} \mathrm{C}$ and provides an indication for the diffusion of substitutional alloying elements.

\section{$\underline{\delta \rightarrow \gamma \text { Transformation (Cooling) }}$}

- Austenite reformation on cooling is observed at both locations. Because of the rapid cooling cycles, the transformation is halted, resulting in a higher ferrite volume fraction than that present in the base metal.

- Differences in the morphology of the austenite phase which forms from both completely transformed and partially transformed microstructures are noted using optical micrsocsopy. The effects of nucleation and growth of austenite from a completely ferritic microstructure and regrowth of austenite from untransformed austenite are observed using TRXRD during the rapid cooling cycles over which austenite reformation occurs.

\section{ACKNOWLEDGMENTS}

This work has been performed under the auspices of the U.S. Department of Energy, by the University of California, Lawrence Livermore National Laboratory under Contract No. W-7405ENG-48. Portions of this research were carried out at the Stanford Synchrotron Radiation Laboratory, a national user facility operated by Stanford University on behalf of the U.S. Department of Energy, Office of Basic Energy Sciences. The ORNL portion of this research was sponsored 
by the U. S. Department of Energy, Division of Materials Science and Engineering, under contract DE-AC05-00OR22725 with UT-Battelle, LLC. The authors would also like to thank Prof. T. DebRoy at The Pennsylvania State University for allowing us the use of the transient heat transfer and fluid flow code for the calculation of weld thermal cycles. Other thanks go to Mr. A.T. Teruya (Lawrence Livermore National Laboratory) for writing the LabView ${ }^{\circledR}$ software used in the control of the welding experiments, Dr. J. Wong (Lawrence Livermore National Laboratory) for his contributions during the performance of these experiments, and Dr. I Hutcheon for performing the electron micro-probe analyses.

\section{REFERENCES}

[1] J.W. Elmer, Joe Wong, M. Fröba, P.A. Waide, and E.M. Larson, Metall. Mater. Trans. A 27A (1996) 775-83.

[2] Joe Wong, M. Froba, J.W. Elmer, P.A. Waide, and E.M. Larson: J. Mat. Sci. 32 (1997) 1493-1500.

[3] J.W. Elmer, Joe Wong, and T. Ressler, Metall. Mater. Trans. A 29A (1998) 2761-2773.

[4] T. Ressler, Joe Wong, and J.W. Elmer, J. Phys. Chem. B 102 (1998) 10724-10735.

[5] Z. Yang, J.W. Elmer, J. Wong, and T. DebRoy, Weld J. 79(4) (2000) 97s-111s.

[6] J.W. Elmer, Joe Wong, and T. Ressler, Metall. Mater. Trans. A 32A (2001) 1175-1188.

[7] J.W. Elmer, Joe Wong, and T. Ressler, Scripta Mater. 43(8) (2000) 751-757.

[8] J.W. Elmer, Joe Wong, and T. Ressler, in Joining of Advanced Specialty Materials II, ASM International, Materials Park, OH, 2000, pp. 200.

[9] T.A. Palmer, J.W. Elmer, and Joe Wong, Sci. Tech. Weld. Join. 7(3) (2002) 159-171.

[10] T.A. Palmer, J.W. Elmer, and Joe Wong, Joining of Advanced and Specialty Materials IV, ASM International, Materials Park, OH, 2002, pp. 108-117.

[11] T.A. Palmer, J.W. Elmer, S.S. Babu, J.M. Vitek, and Joe Wong, in S.A. David, T. DebRoy, J.C. Lippold, H.B. Smartt, and J.M. Vitek (Eds), Trends in Welding Research, ASM International, Materials Park, OH, 2003, pp. 23-28.

[12] W. Zhang, J.W. Elmer, and T. DebRoy, Scripta Mater. 46 (2002) 753.

[13] W. Zhang, J.W. Elmer, and T. DebRoy, Mater Sci Eng A. 333 (1-2) (2002) 320.

[14] W. Zhang, J.W. Elmer, and T. DebRoy, in S.A. David, T. DebRoy, J.C. Lippold, H.B. Smartt, and J.M. Vitek (Eds.), Trends in Welding Research, ASM International, Materials Park, OH, 2003, pp. 180-185.

[15] J. W. Elmer, T. A. Palmer, W. Zhang, B. Wood, and T. DebRoy, Acta Materialia 51 (2003) 3333-3349. 
[16] S.S. Babu, J.W. Elmer, S.A. David, and M.A. Quintana, Proc. R. Soc. Lond. A 458 (2002) 811-821.

[17] S.S. Babu, J.W. Elmer, J.M. Vitek, and S.A. David, Acta Materiala 50 (2002) 4763-4781.

[18] J. Wong, T. Ressler, and J.W. Elmer, J. Synchrotron Radiation 10(2) (2003) 154-167.

[19] H. Hemmer and Ø. Grong, Metall. Mater. Trans. A, 30A (1999) 2915-2929.

[20] H. Hemmer, Ø. Grong, and S. Klokkehaug, Metall. Mater. Trans. A 31A (2000) 10351048.

[21] S. Hertzman, P.J. Ferreira, and B. Brolund, Metall. Mater. Trans. A, 28A (1997) 277-285.

[22] P.D. Southwick and R.W.K Honeycombe, Metal Sci. 14 (1980) 253-261.

[23] S. Atamert and J.E. King, Acta Metall. Mater. 39(3) (1991) 273-285.

[24] T.H. Chen and J.R. Yang, Mater. Sci Eng. A. A338 (2002) 166-181.

[25] S. Atamert and J.E. King, Mater. Sci. Technol. 8 (1992) 896-911.

[26] Designation A923-98, Annual Book of ASTM Standards, vol. 01.03, p 501, American Society for Testing and Materials West Conshohocken, PA, 1998.

[27] V. Karpenko, J.H. Kinney, S. Kulkarni, K. Neufeld, C. Poppe, K.G. Tirsell, J. Wong, J. Cerino, T. Troxel, J. Yang, E. Hoyer, M. Green, D. Humpries, S. Marks, and D. Plate, Rev. Sci. Instrum. 60 (1989) 1451-1460

[28] PowderCell, v. 1.0, Federal Institute for Materials Research and Testing, Rudower Chaussee 5, 12489 Berlin, Germany

[29] B.D. Cullity and S.R. Stock, Elements of X-Ray Diffraction, Third Edition, Prentice Hall, Upper Saddle River, NJ, 2001

[30] W. Zhang, G.G. Roy, J.W. Elmer, and T. DebRoy, J. Appl. Phys. 93(5), (2003) 3022-3033.

[31] Z. Yang and T. Debroy: Metall. Mater. Trans. B 30B (1999) 483-493.

[32] T.A. Palmer, J.W. Elmer, S.S. Babu, and J.M. Vitek, in E.B. Damm and M. Merwin (Eds.), Austenite Formation and Decomposition, ISS/TMS, Warrendale, PA, 2003, pp.177-192.

[33] J.-O. Nilsson, Mater Sci. Technol. 8 (1992) 685-700.

[34] Nilsson and Wilson, Mater Sci. Technol. 9 (1993) 545-554.

[35] Nilsson, Karlsson, and Andersson, Mater Sci. Technol. 11 (1995) 276-283.

[36] L. Karlsson, WRC Bulletin 438, 1999.

[37] A.J. Ramirez, J.C. Lippold, and S.D. Brandi, Metall. Mater. Trans. A 34A, (2003) 15751597. 


\section{List of Tables}

Table 1. Summary of spot welding parameters used in the TRXRD experiments.

Table 2. Summary of area/volume fractions measured in the base metal using both quantitative metallography and the measurement of peak areas in the TRXRD patterns.

Table 3. Summary of characteristics for each TRXRD experimental run.

Table 4. Summary of material and numerical scheme parameters used in the spot weld modeling calculations for 2205 DSS spot welds.

Table 5. Summary of the characteristics of the complete transformation sequence observed at Location A.

Table 6. Summary of the characteristics of the partial transformation sequence observed at Location $\mathrm{B}$. 


\section{$\underline{\text { List of Figures }}$}

Figure 1. Schematic diagram of TRXRD experimental set-up.

Figure 2(a\&b). Plots of calculated thermal profiles and fluid velocities (a) on the top surface and (b) across the weld cross section in a 2205 DSS spot weld with an arc on time of 20 seconds.

Figure 3. Calculated thermal profiles at locations in the HAZ corresponding to the monitoring locations during the TRXRD measurements.

Figure 4(a-c). Plots showing variations in peak intensities (a) over the course of the TRXRD run, (b) during the heating cycle, and (c) during the cooling cycle at a location in the HAZ directly adjacent to the fusion zone.

Figure 5. Plot showing the changes in both the ferrite volume fraction and the temperatures experienced at each corresponding time at Location A over the course of the TRXRD run.

Figure 6(a\&b). Plot showing (a) the ferrite and austenite lattice parameters and (b) the variations in the FWHM values for the fcc(111) and bcc(110) peaks over the course of the TRXRD run at Location A.

Figure 7. Plot showing variations in peak intensities over the course of the TRXRD run at Location B.

Figure 8. Plot showing variations in the ferrite volume fractions over the course of the TRXRD run at a Location B.

Figure 9(a\&b). Plot showing (a) the variations in the ferrite and austenite lattice parameters and (b) the measured FWHM values for the fcc(111) and bcc(110) peaks over the course of the TRXRD run at Location B.

Figure 10(a\&b). Plots showing typical alloying element partitioning behavior between the ferrite and austenite grains in the 2205 DSS base metal for (a) the primary substitutional alloying elements and (b) nitrogen.

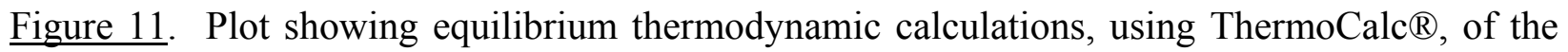
stability of the ferrite, austenite, and liquid phases in the 2205 Duplex Stainless Steel analyzed here.

Figure 12(a-c). Micrographs showing the various regions of the HAZ in the 2205 DSS spot weld: (a) fusion zone/HAZ boundary, (b) fully transformed/partially transformed regions, and (c) annealed/base metal regions.

Figure 13(a\&b). Micrographs taken at higher magnifications in the spot weld HAZ in the vicinity of (a) Location A and (b) Location B, showing differences in the observed morphology of the austenite grains. 
Table 1. Summary of spot welding parameters used in the TRXRD experiments.

\begin{tabular}{|l|c|}
\hline Welding Electrode & W-2\% Th \\
\hline Electrode Diameter $(\mathrm{cm})$ & 0.47 \\
\hline Torch Polarity & DCEN \\
\hline Maximum Current $(\mathrm{A})$ & 130 \\
\hline Background Current $(\mathrm{A})$ & 90 \\
\hline Pulsing Frequency $(\mathrm{Hz})$ & 300 \\
\hline Peak On Time $(\%)$ & 50 \\
\hline Arc Gap (cm) & 0.28 \\
\hline Weld Voltage $(\mathrm{V})$ & 17 \\
\hline Shielding Gas & Helium \\
\hline Arc On Times (sec) & 17,20 \\
\hline
\end{tabular}


Table 2. Summary of area/volume fractions measured in the base metal using both quantitative metallography and the measurement of peak areas in the TRXRD patterns.

\begin{tabular}{|l|c|c|c|c|}
\cline { 2 - 5 } \multicolumn{1}{c|}{} & \multicolumn{2}{c|}{ Average Value } & \multicolumn{2}{c|}{ Standard Deviation } \\
\cline { 2 - 5 } \multicolumn{1}{c|}{} & $\frac{\text { Ferrite }}{(\mathrm{bcc})}$ & $\frac{\text { Austenite }}{(\mathrm{fcc})}$ & $\frac{\text { Ferrite }}{(\mathrm{bcc})}$ & $\frac{\text { Austenite }}{(\mathrm{fcc})}$ \\
\hline Quantitative Metallography & 0.54 & 0.460 & 0.038 & 0.038 \\
\hline Peak Area Measurements & 0.642 & 0.358 & 0.009 & 0.009 \\
\hline Calibration Factors $\left(C_{\delta}\right.$ and $\left.C_{\gamma}\right)$ & 0.840 & 1.287 & --- & -- \\
\hline
\end{tabular}


Table 3. Summary of characteristics for each TRXRD experimental run.

\begin{tabular}{|c|c|c|c|l|c|c|}
\hline & & & & Distance of X-Ray Beam From \\
\hline $\begin{array}{c}\text { Beam } \\
\text { Location }\end{array}$ & $\begin{array}{c}\text { Arc On } \\
\text { Time (sec) }\end{array}$ & $\begin{array}{c}\text { Exposure } \\
\text { Time/Frame } \\
(\mathbf{m s e c})\end{array}$ & $\begin{array}{c}\text { Average } \\
\text { Diameter } \\
(\mathbf{m m})\end{array}$ & Observed Transformation & $\begin{array}{c}\text { Weld Center } \\
(\mathbf{m m})\end{array}$ & $\begin{array}{c}\text { FZ Boundary } \\
(\mathbf{m m})\end{array}$ \\
\hline A & 17 & 100 & 10.65 & Complete Transformation & 5.4 & 0.2 \\
\hline B & 20 & 200 & 10.45 & Partial Transformation & 6.4 & 0.7 \\
\hline
\end{tabular}


Table 4. Summary of material and numerical scheme parameters used in the spot weld modeling calculations for 2205 DSS spot welds.

\begin{tabular}{|l|c|c|}
\hline \multicolumn{1}{|c|}{ Property } & Value & Reference \\
\hline Liquidus Temperature $(\mathrm{K})$ & 1715 & $*$ \\
\hline Solidus Temperature $(\mathrm{K})$ & 1589 & $37^{* *}$ \\
\hline Density of Liquid $\left(\mathrm{kg} / \mathrm{m}^{3}\right)$ & 7200 & 38 \\
\hline Enthalpy of Solid at Melting Point $(\mathrm{J} / \mathrm{kg})$ & $1.05 \times 10^{6}$ & 38 \\
\hline Enthalpy of Liquid at Melting Point $(\mathrm{J} / \mathrm{kg})$ & $1.32 \times 10^{6}$ & 37 \\
\hline Specific Heat of Solid (J/kg-K) & 418.68 & 37 \\
\hline Specific Heat of Liquid (J/kg-K) & 808.05 & $37^{* *}$ \\
\hline Thermal Conductivity of Solid (W/m-K) & 18.83 & $37^{* *}$ \\
\hline Thermal Conductivity of Liquid (W/m-K) & 41.84 & 37 \\
\hline $\begin{array}{l}\text { Viscosity of Liquid } \\
(\mathrm{kg} / \mathrm{m}-\mathrm{Sec})\end{array}$ & 0.0085 & $37^{* *}$ \\
\hline $\begin{array}{l}\text { Temperature Coefficient of Surface } \\
\text { Tension (N/m-K) }\end{array}$ & $-9.25 \times 10^{-4}$ & 37 \\
\hline Coefficient of Thermal Expansion (1/K) & $1.00 \times 10^{-5}$ & \\
\hline Arc Radius (cm) & 0.275 & \\
\hline Arc Efficiency (\%) & 40 & \\
\hline Time Step (sec) & 17,20 & \\
\hline Arc On Times (sec) & & \\
\hline
\end{tabular}

* Values are based on calculations provided by ThermoCalc for an alloy of this composition.

** Values are based on approximations from pure metal values. 
Table 5. Summary of the characteristics of the complete transformation sequence observed at Location A.

\begin{tabular}{|c|c|c|c|c|c|c|}
\hline & & \multicolumn{2}{|c|}{ Heating } & \multirow[b]{2}{*}{$\underline{\operatorname{Arc} \text { Off }}$} & \multicolumn{2}{|c|}{ Cooling } \\
\hline & $\underline{\text { Original Values }}$ & $\underset{\text { Initiation }}{\gamma \rightarrow \delta}$ & $\underset{\text { Completion }}{\stackrel{\gamma \rightarrow \delta}{\text { complion }}}$ & & $\underset{\text { Initiation }}{\frac{\delta \rightarrow \gamma}{\text { nation }}}$ & $\frac{\text { TRXRD Run }}{\text { End }}$ \\
\hline Time (sec) & ---- & 5.2 & 12.8 & 17.6 & 22.4 & 60 \\
\hline Temperature $\left({ }^{\circ} \mathrm{C}\right)$ & 25 & 1068 & 1342 & 1412 & 333 & 41 \\
\hline \multicolumn{7}{|c|}{ Ferrite Volume Fraction } \\
\hline & 47.5 & 70.4 & 100 & 100 & 99.4 & 78.7 \\
\hline \multicolumn{7}{|c|}{ Lattice Parameter $(A)$} \\
\hline Austenite & 3.6034 & 3.6787 & $\begin{array}{c}--- \\
\end{array}$ & $\begin{array}{c}--- \\
\end{array}$ & 3.6320 & 3.6182 \\
\hline Ferrite & 2.8781 & 2.9147 & 2.9183 & 2.9176 & 2.8782 & 2.8772 \\
\hline \multicolumn{7}{|l|}{ FWHM } \\
\hline$f c c(111)$ & 0.2034 & 0.1191 & $\begin{array}{ll}--- \\
\end{array}$ & ---- & 0.0496 & 0.1023 \\
\hline$b c c(110)$ & 0.2166 & 0.0561 & 0.0187 & 0.0124 & 0.0215 & 0.0334 \\
\hline
\end{tabular}


Table 6. Summary of the characteristics of the partial transformation sequence observed at Location B.

\begin{tabular}{|c|c|c|c|c|c|c|}
\hline & & \multicolumn{2}{|c|}{ Heating } & \multirow[b]{2}{*}{$\underline{\text { Arc Off }}$} & \multicolumn{2}{|c|}{ Cooling } \\
\hline & $\frac{\text { Original }}{\text { Values }}$ & $\underset{\text { Initiation }}{\gamma \rightarrow \delta}$ & $\frac{\text { Beginning of }}{\text { Speckling }}$ & & $\begin{array}{l}\text { End of } \\
\text { Speckling }\end{array}$ & $\frac{\text { TRXRD Run }}{\text { End }}$ \\
\hline Time (sec) & 0 & 6.3 & 19.1 & 22.1 & 26.2 & 60 \\
\hline Temperature $\left({ }^{\circ} \mathrm{C}\right)$ & 25 & 725 & 1046 & 1075 & 433 & 58 \\
\hline \multicolumn{7}{|c|}{ Ferrite Volume Fraction } \\
\hline & 50.2 & 55.5 & 60.6 & $\begin{array}{ll}--- \\
\end{array}$ & 71.2 & 69.7 \\
\hline \multicolumn{7}{|c|}{ Lattice Parameter $(A)$} \\
\hline Austenite & 3.4908 & 3.5244 & 3.5349 & 3.5350 & 3.5069 & 3.4902 \\
\hline Ferrite & 2.7797 & 2.7932 & 2.8051 & ---- & 2.7825 & 2.7773 \\
\hline \multicolumn{7}{|l|}{ FWHM } \\
\hline$f c c(111)$ & 0.2205 & 0.1950 & 0.1055 & 0.1060 & 0.1167 & 0.1288 \\
\hline$b c c(110)$ & 0.2042 & 0.1672 & 0.0780 & ---- & 0.0652 & 0.0729 \\
\hline
\end{tabular}




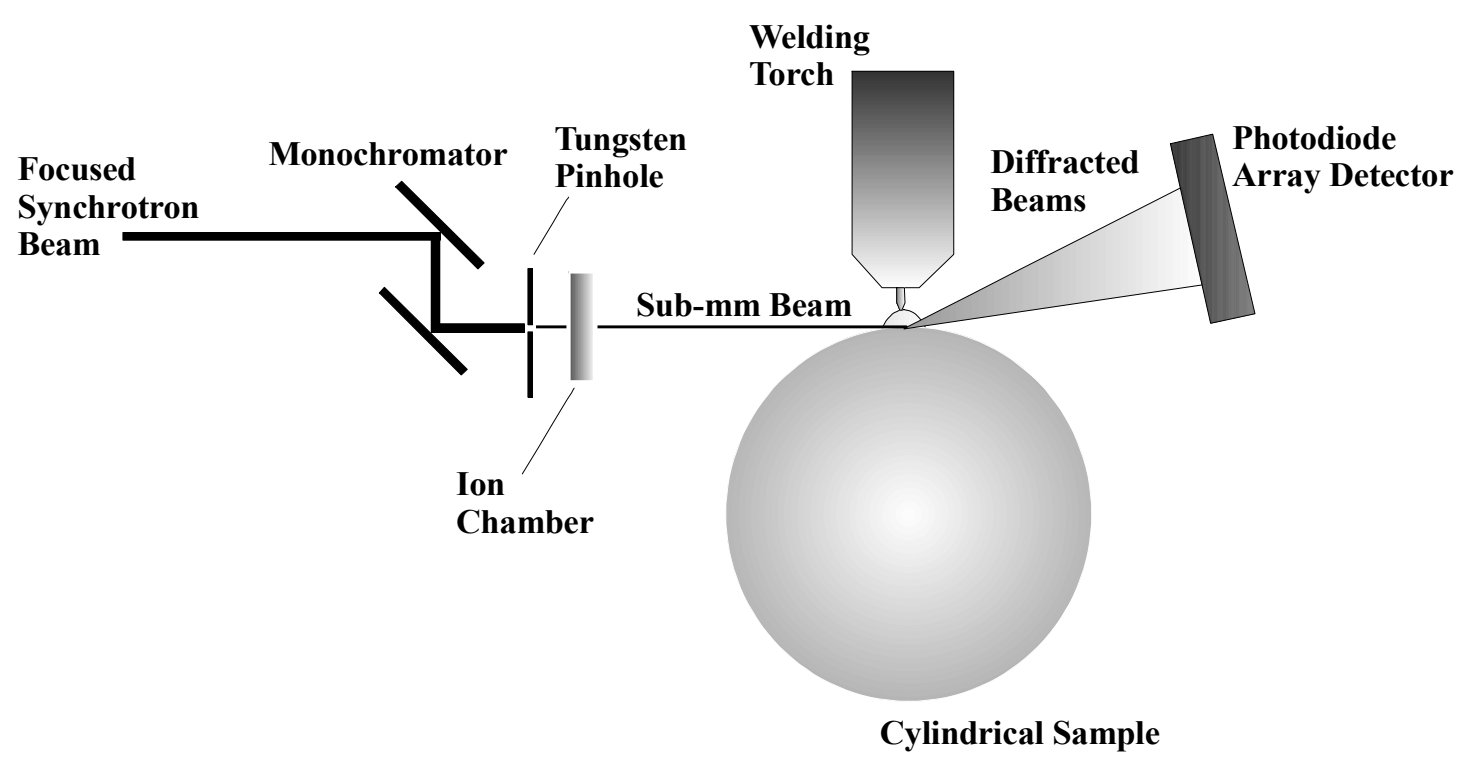

Figure 1. Schematic diagram of TRXRD experimental set-up. 


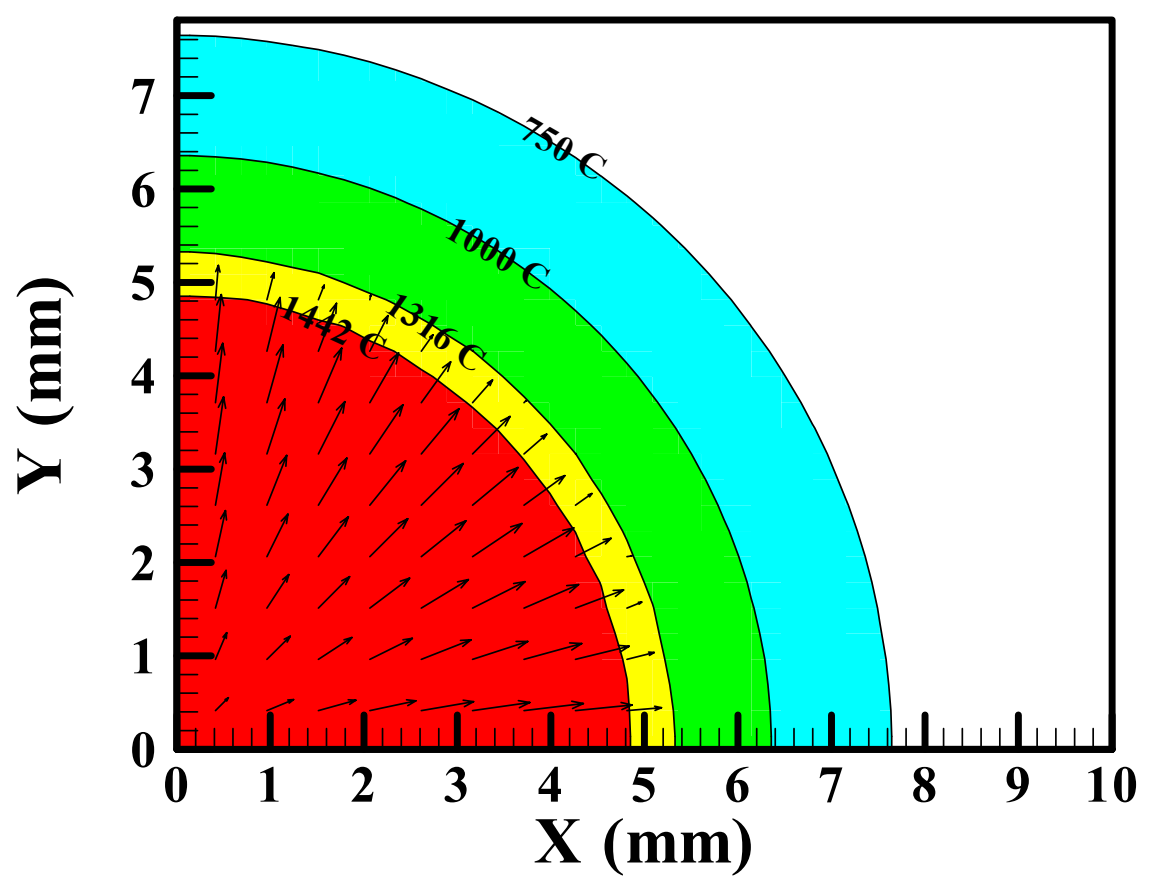

(a)

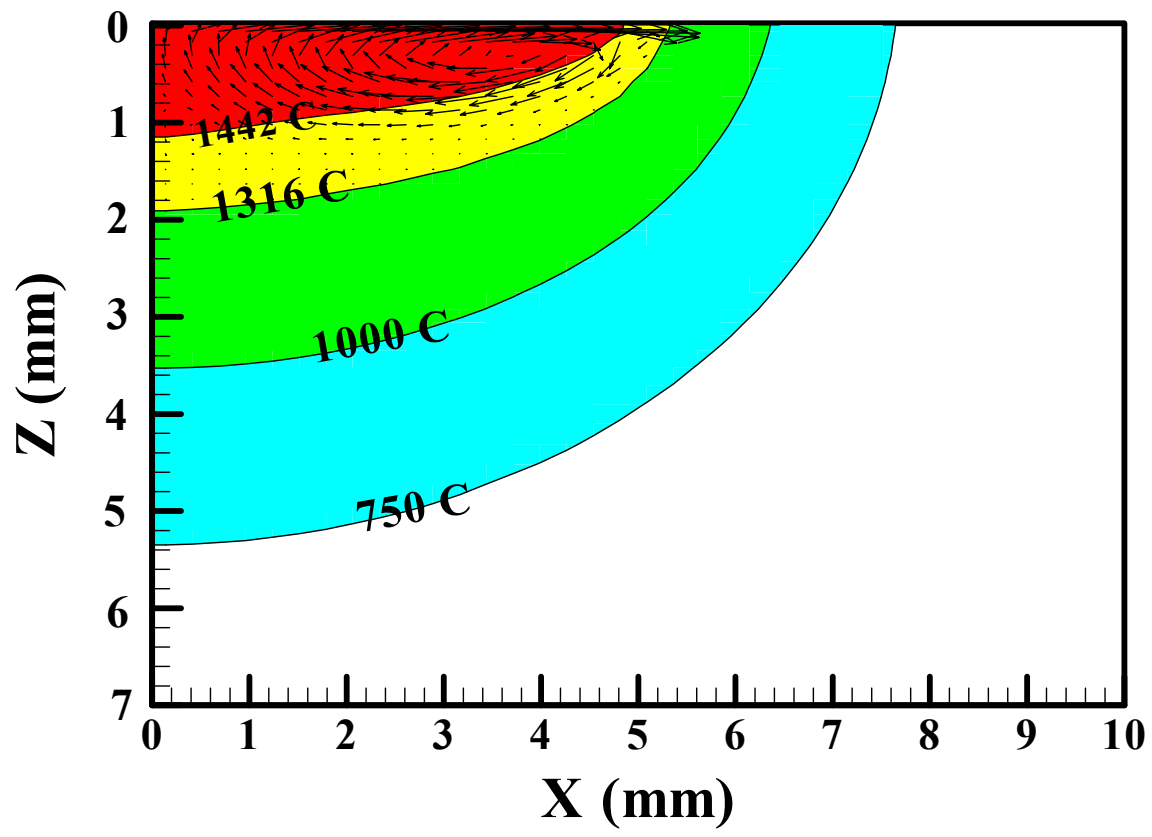

(b)

Figure 2(a\&b). Plots of calculated thermal profiles and fluid velocities (a) on the top surface and (b) across the weld cross section in a 2205 DSS spot weld with an arc on time of 20 seconds. 


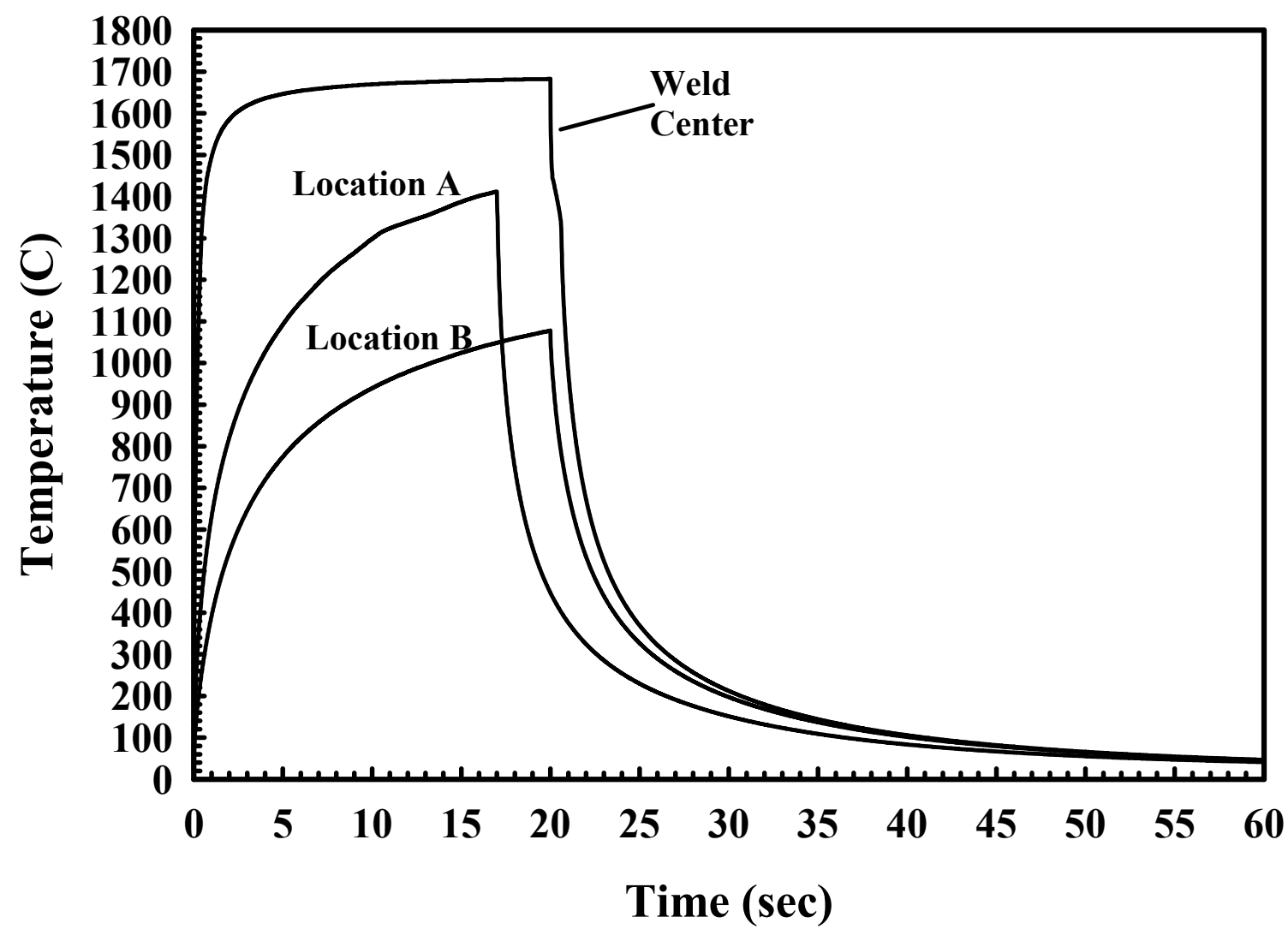

Figure 3. Calculated thermal profiles at locations in the HAZ and fusion zone of spot weld used in the TRXRD experiments. The two primary monitoring locations used during the TRXRD measurements are labeled as Location A and Location B. 


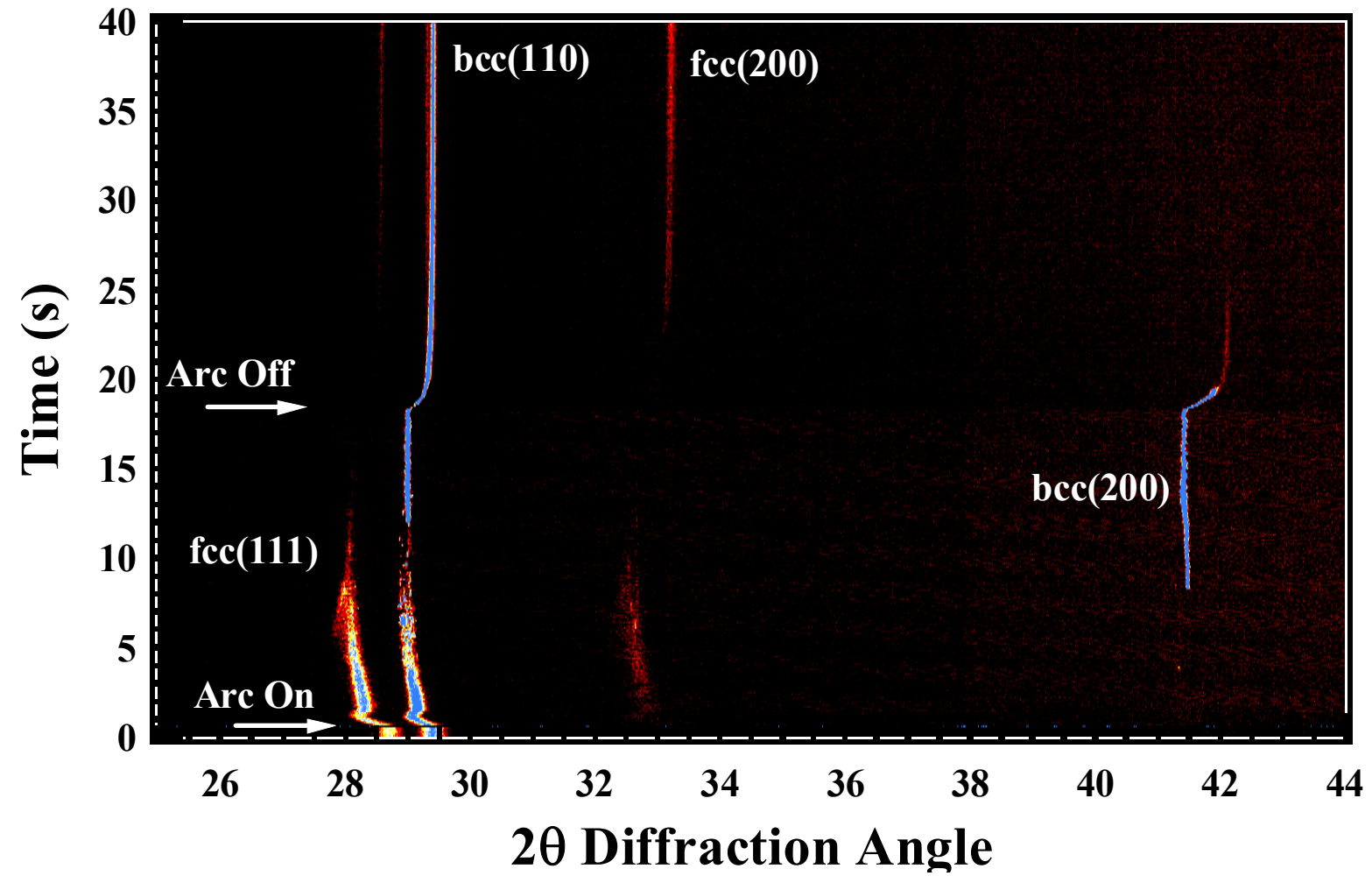

Figure 4. Plot showing variations in the peak intensities over the course of the TRXRD run at a location in the HAZ directly adjacent to the fusion zone. 


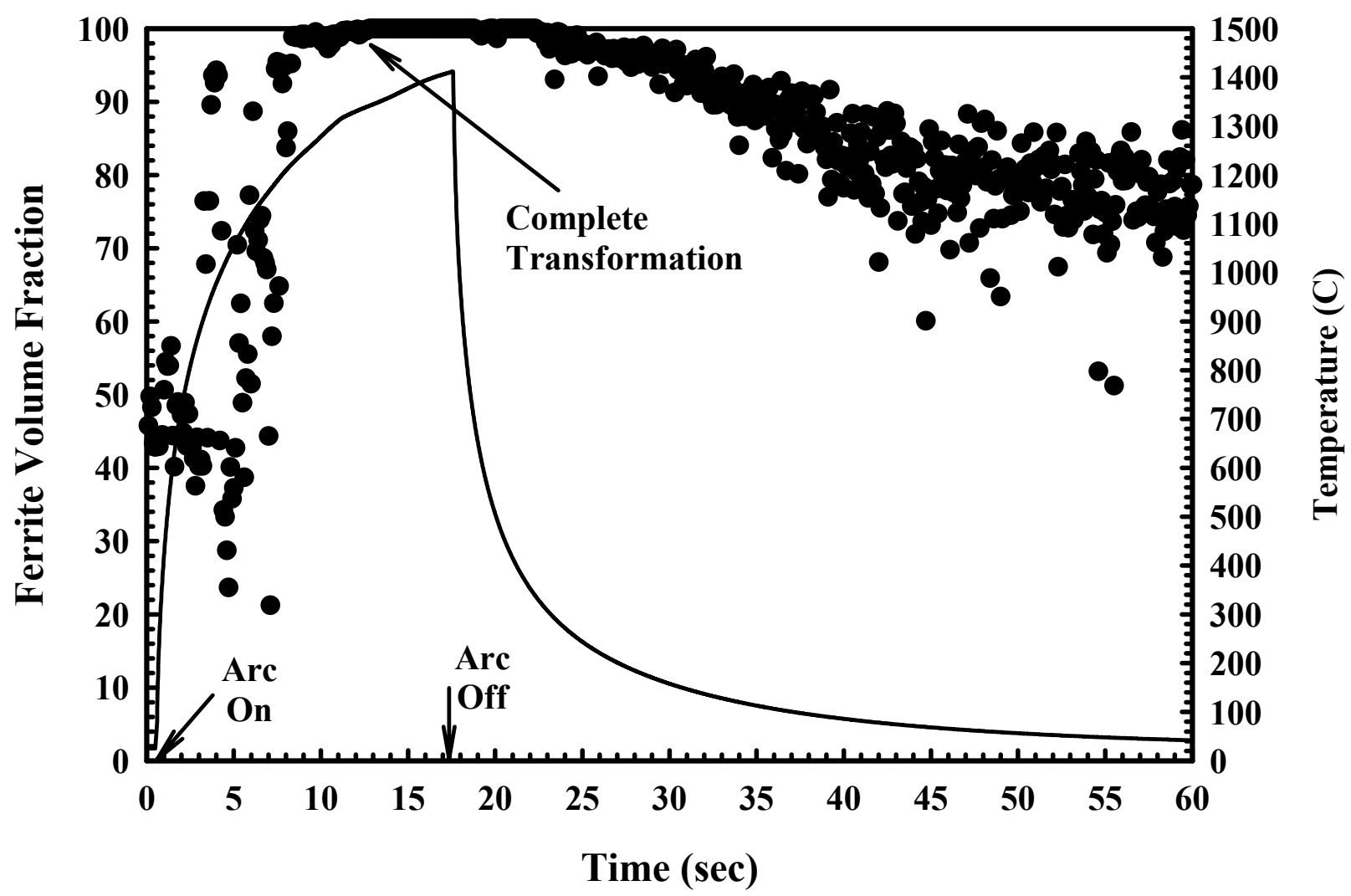

Figure 5. Plot showing the changes in both the ferrite volume fraction and the temperatures experienced at each corresponding time at Location A over the course of the TRXRD run. 


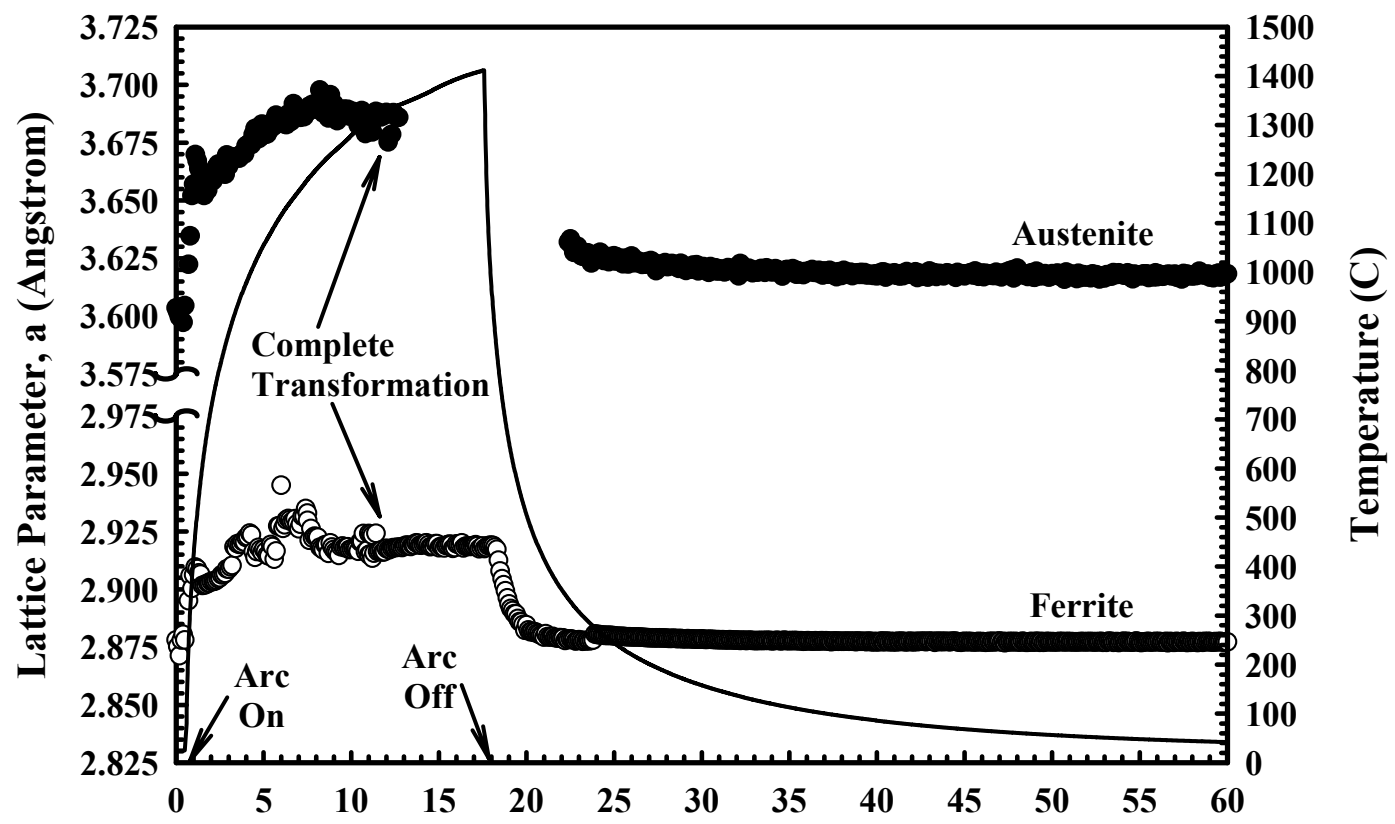

Time (sec)

(a)

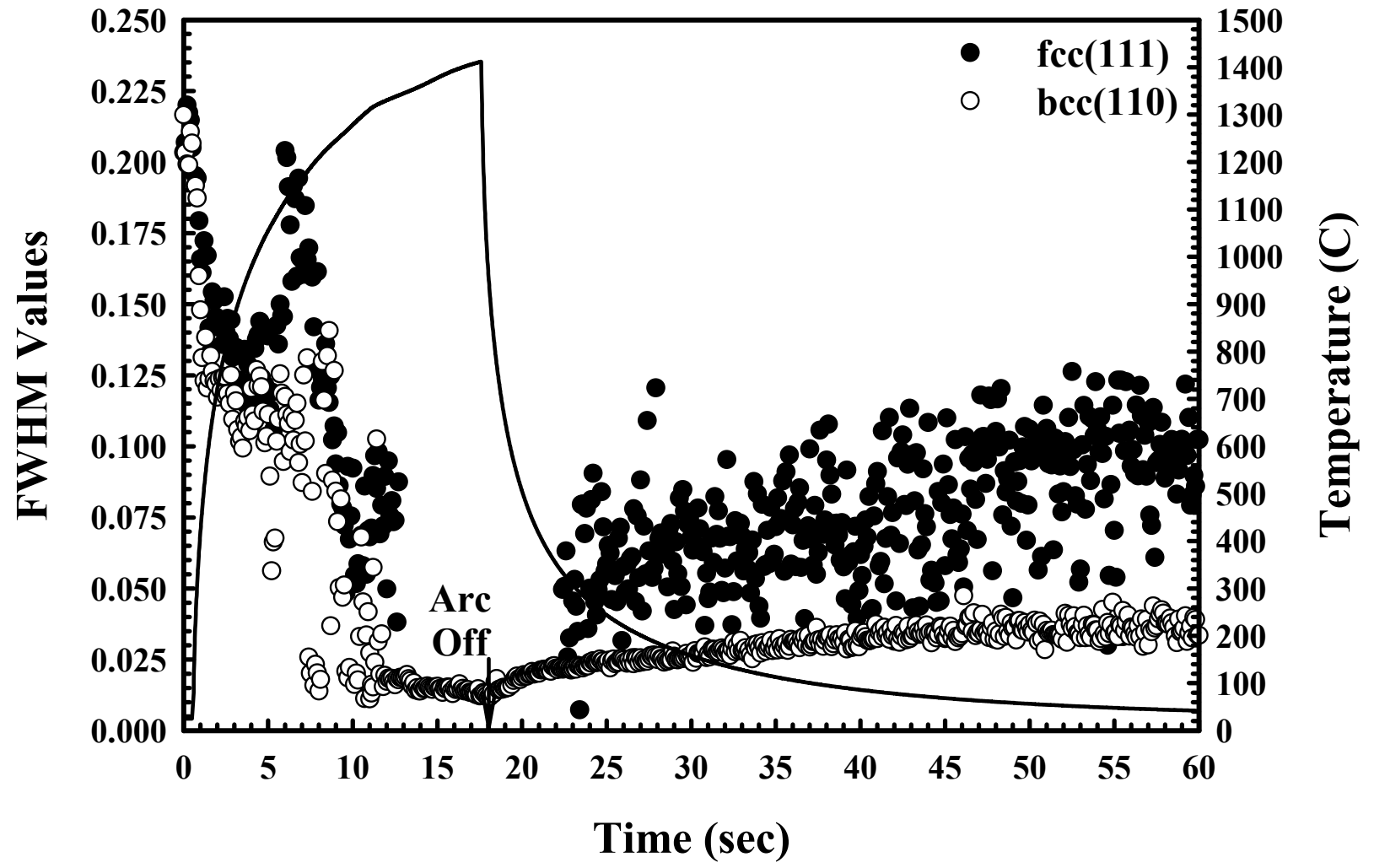

(b)

Figure 6(a\&b). Plot showing (a) the ferrite and austenite lattice parameters and (b) the variations in the FWHM values for the fcc(111) and bcc(110) peaks over the course of the TRXRD run at Location A. 


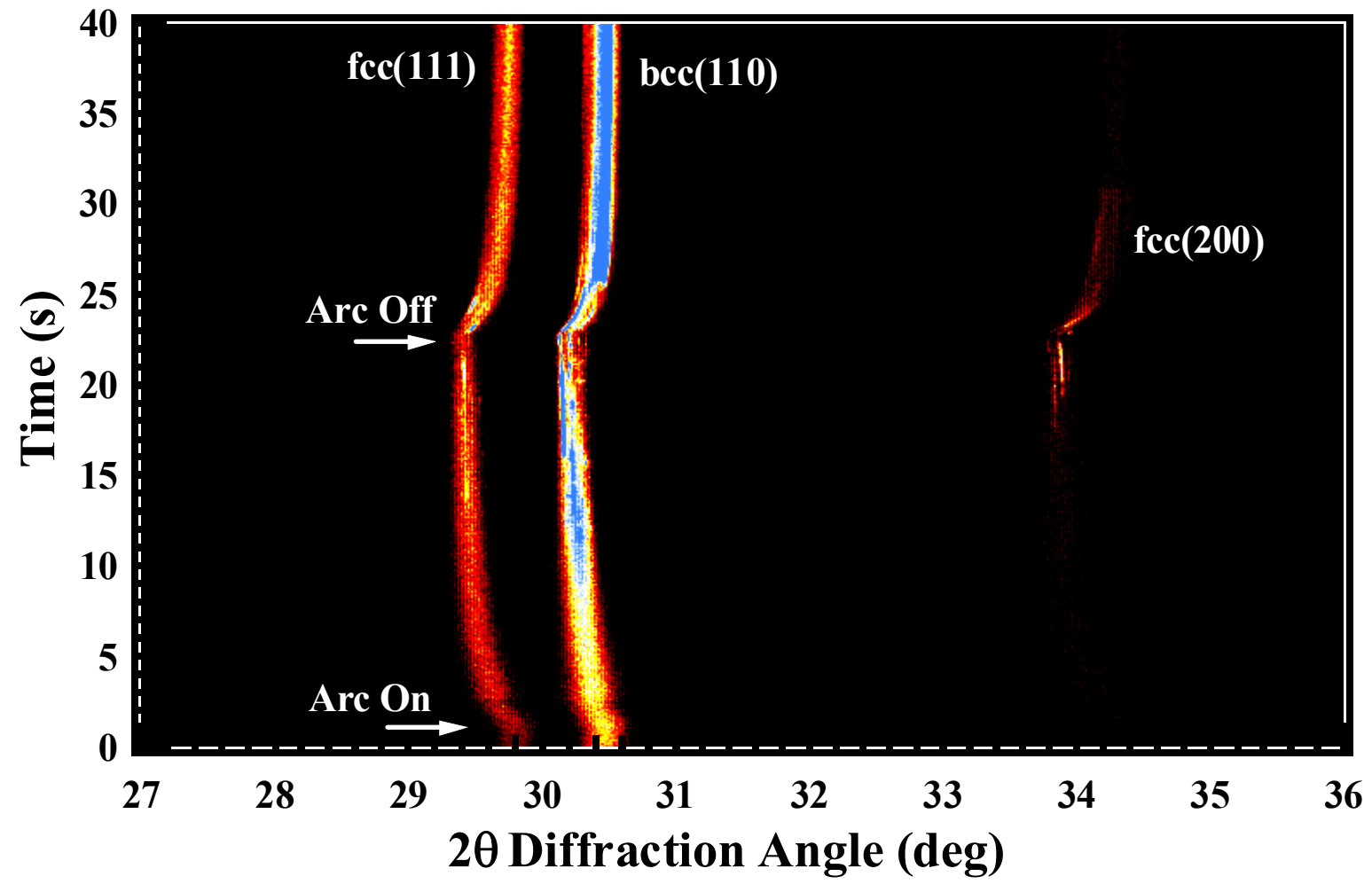

Figure 7. Plot showing variations in peak intensities over the course of the TRXRD run at Location B. 


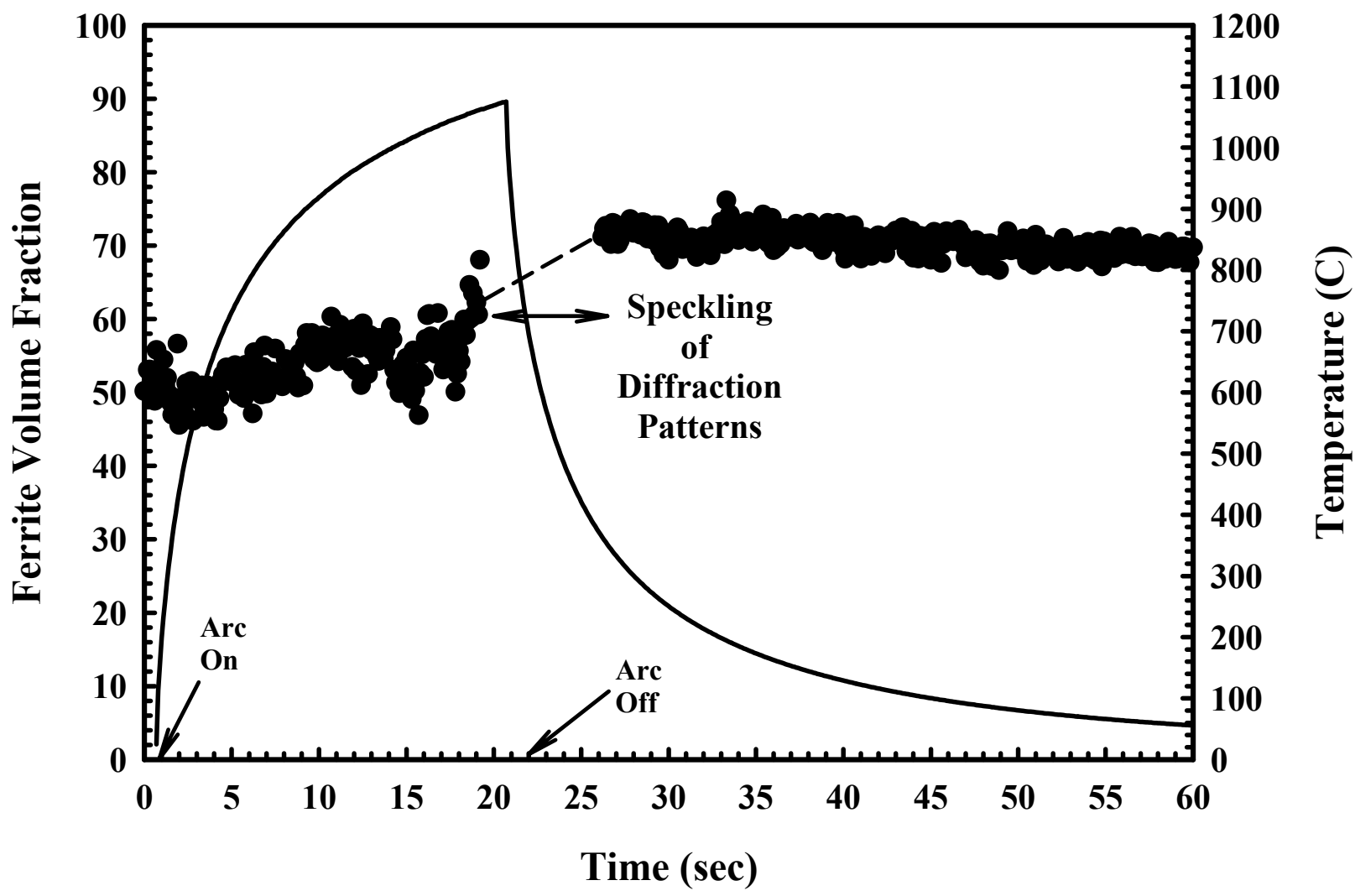

Figure 8. Plot showing variations in the ferrite volume fractions over the course of the TRXRD run at a Location $B$. 


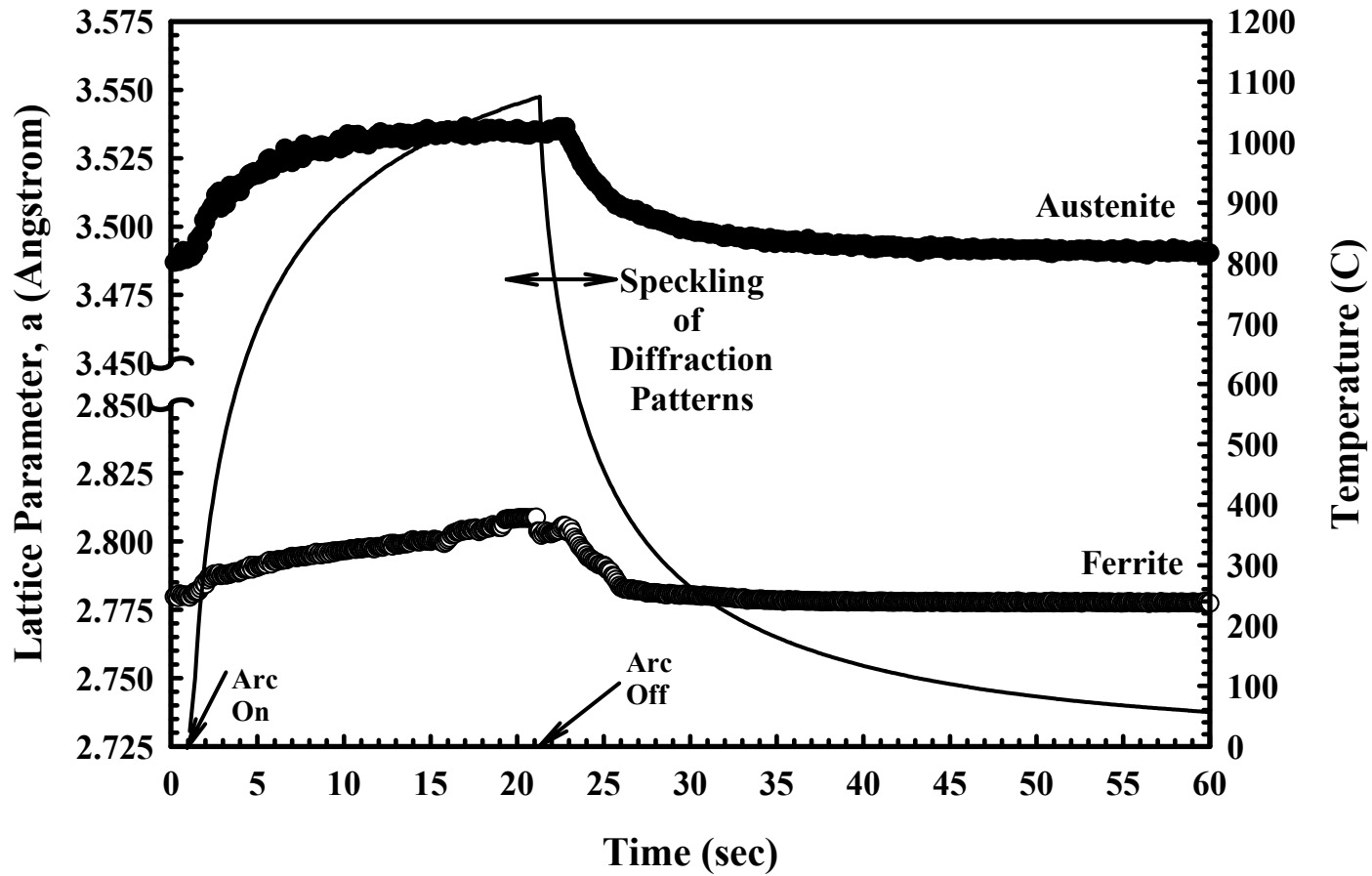

(a)

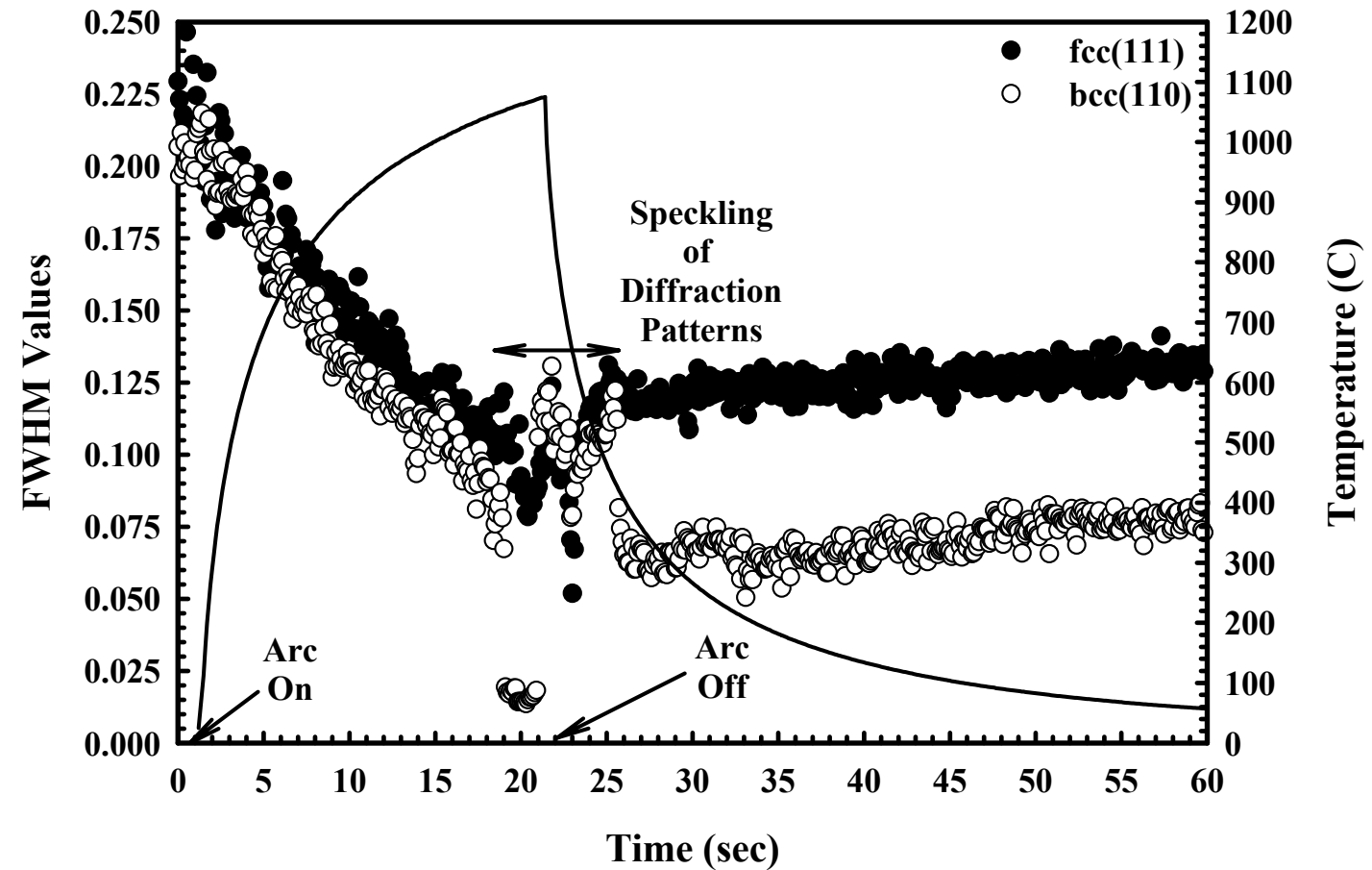

(b)

Figure 9(a\&b). Plot showing (a) the variations in the ferrite and austenite lattice parameters and (b) the measured FWHM values for the fcc(111) and bcc(110) peaks over the course of the TRXRD run at Location B. 


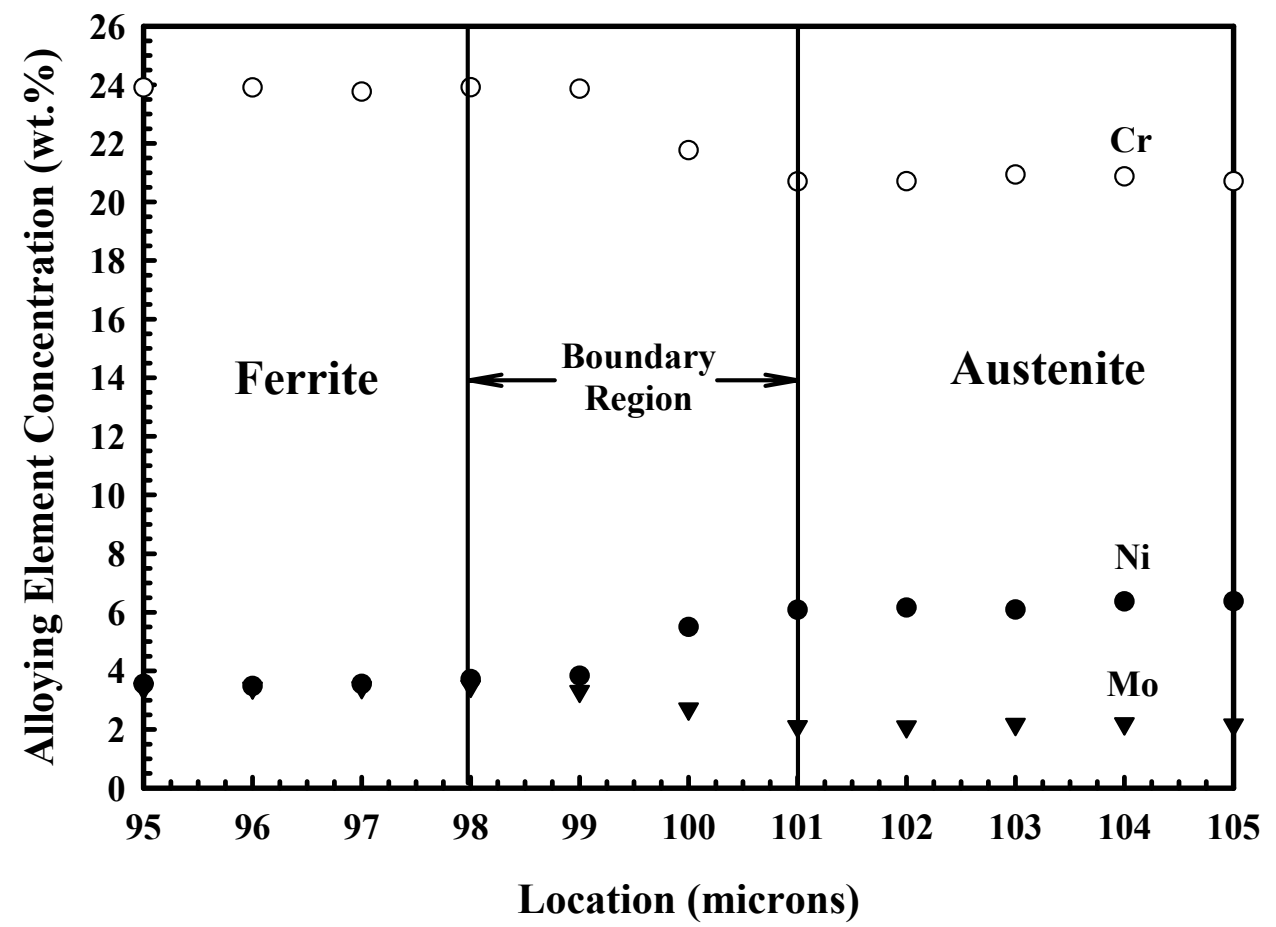

(a)

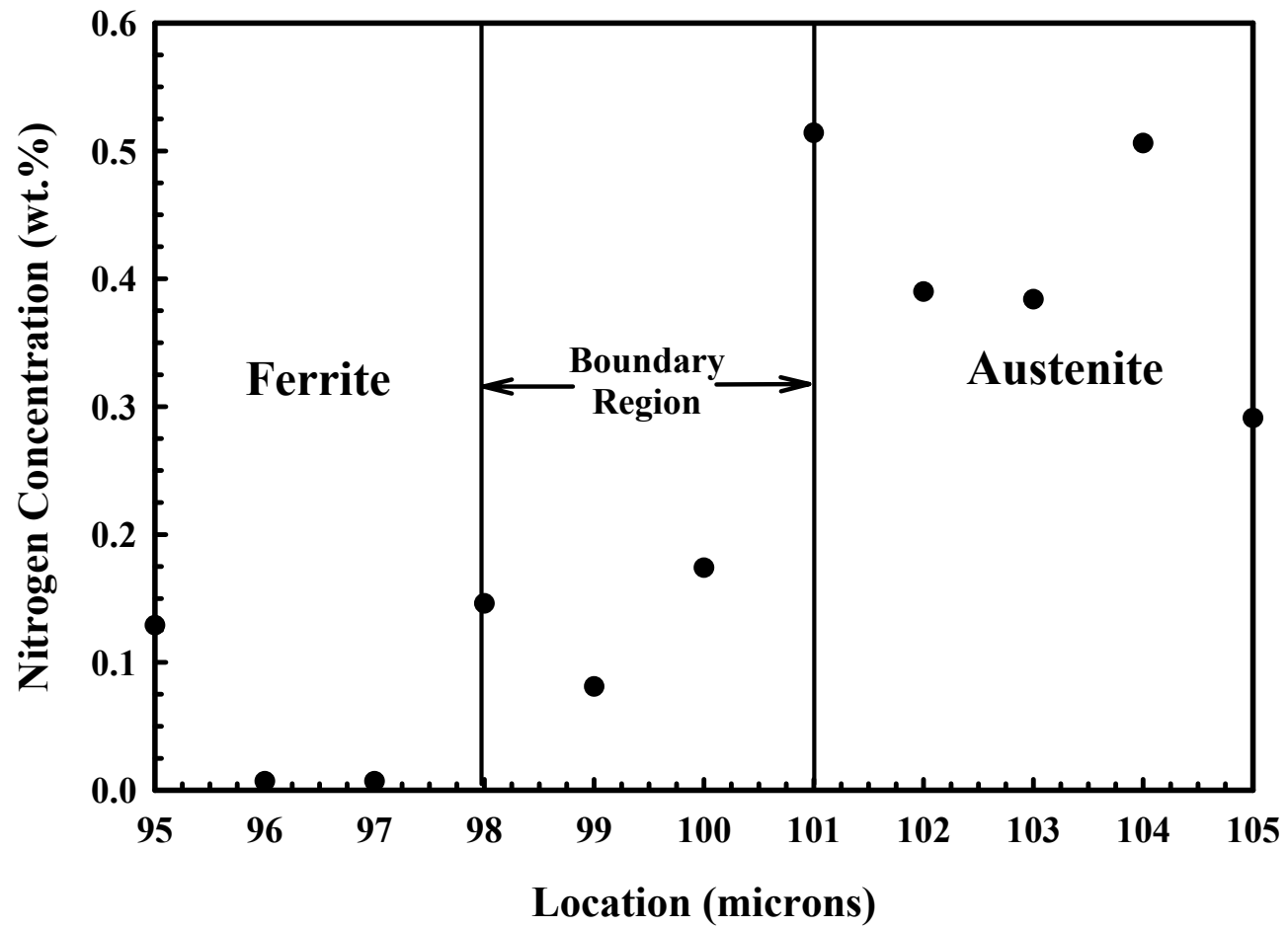

(b)

Figure $10(\mathrm{a} \& \mathrm{~b})$. Plots showing typical alloying element partitioning behavior between the ferrite and austenite grains in the 2205 DSS base metal for (a) the primary substitutional alloying elements and (b) nitrogen. 


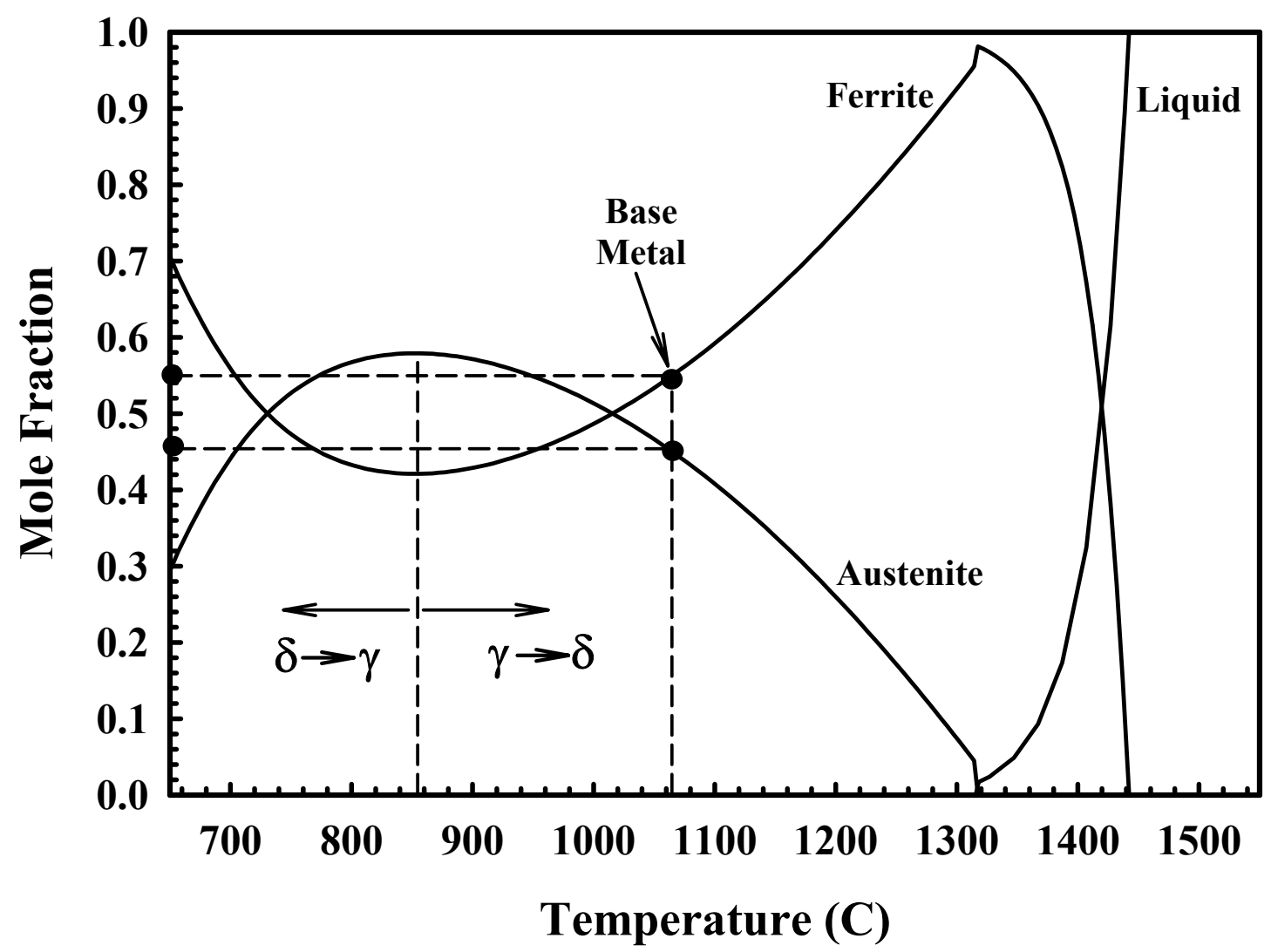

Figure 11. Plot showing equilibrium thermodynamic calculations, using ThermoCalc $₫$, of the stability of the ferrite, austenite, and liquid phases in the 2205 Duplex Stainless Steel analyzed here. 


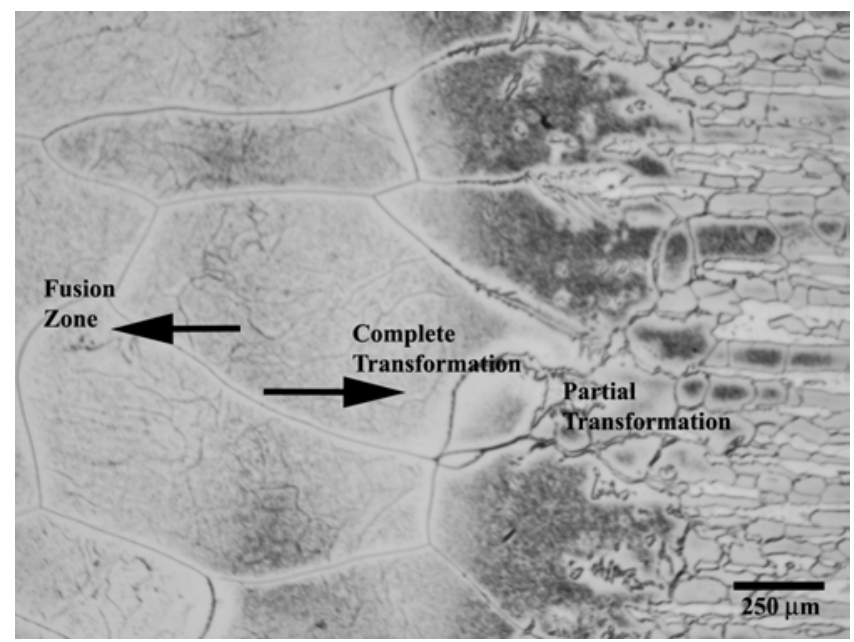

(a)

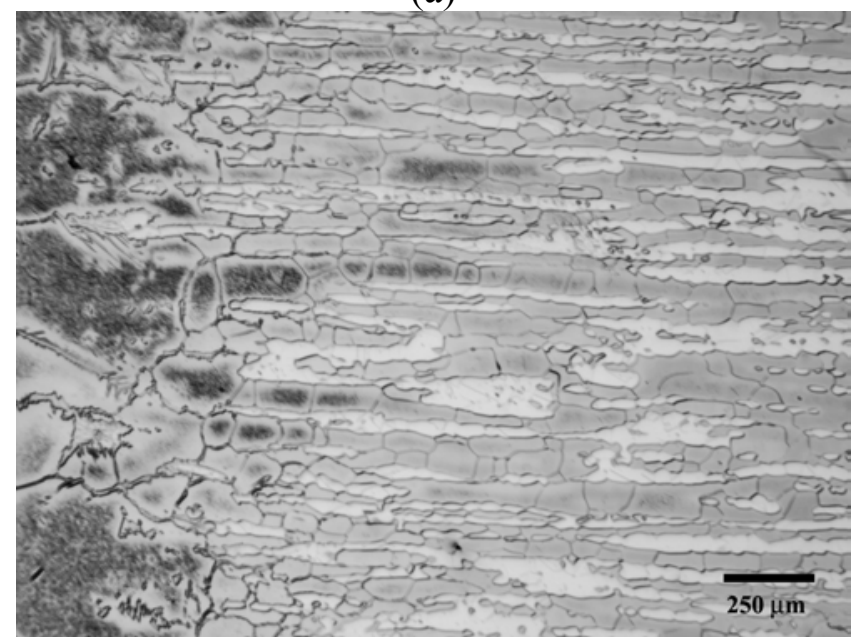

(b)

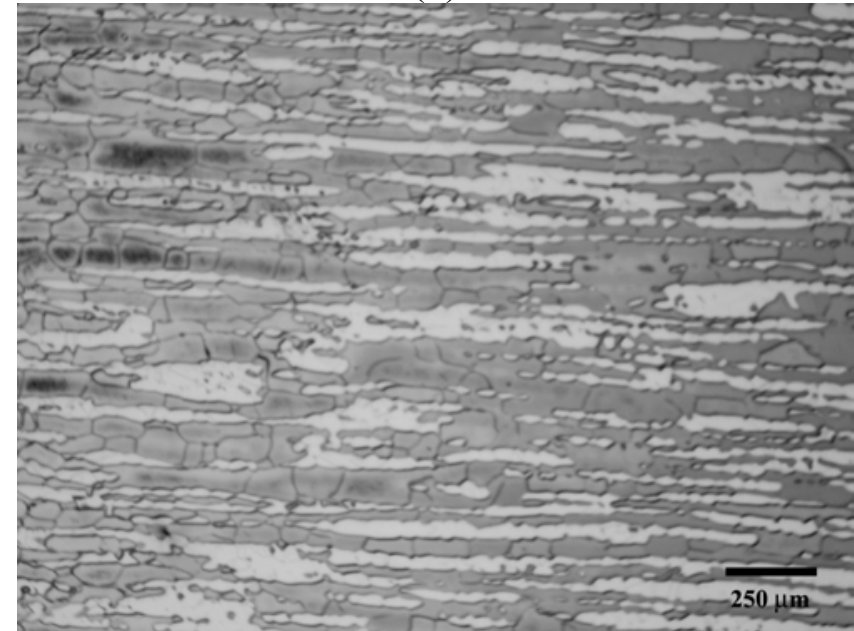

(c)

Figure 12(a-c). Micrographs showing the various regions of the HAZ in the 2205 DSS spot weld: (a) fusion zone/HAZ boundary, (b) fully transformed/partially transformed regions, and (c) annealed/base metal regions. 


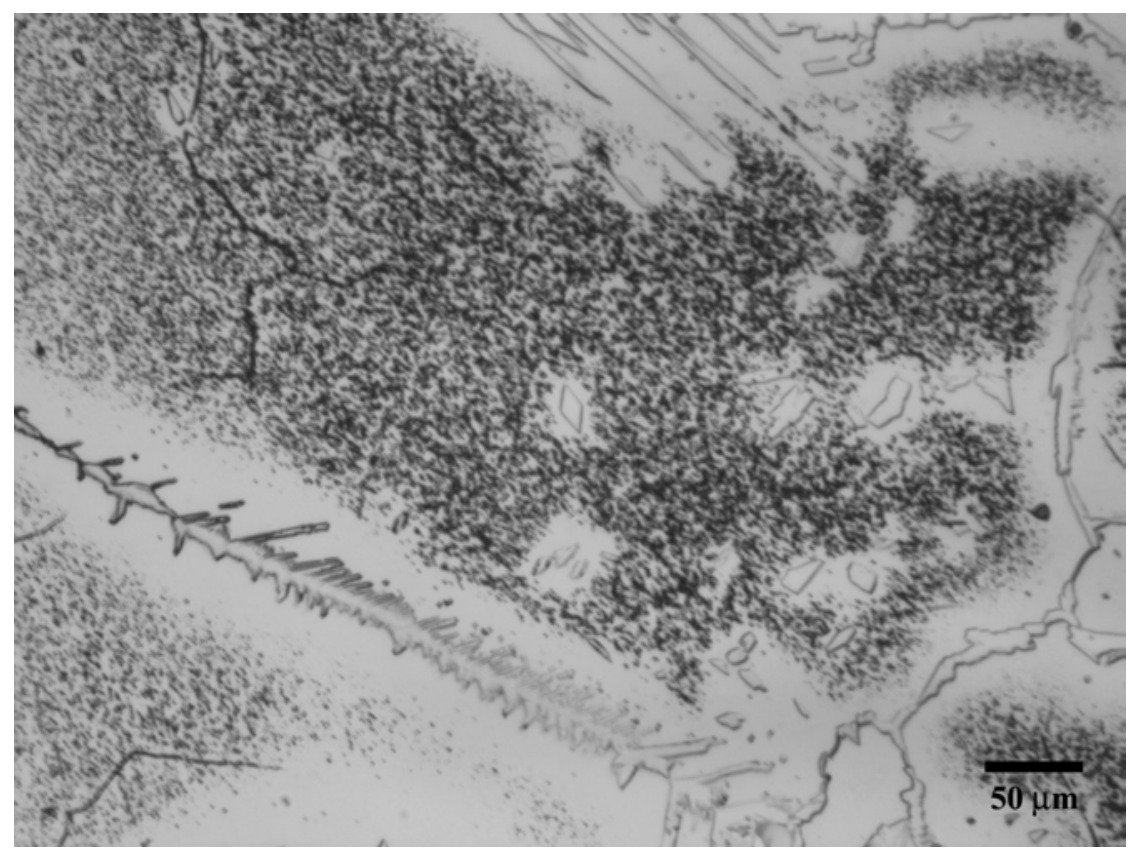

(a)

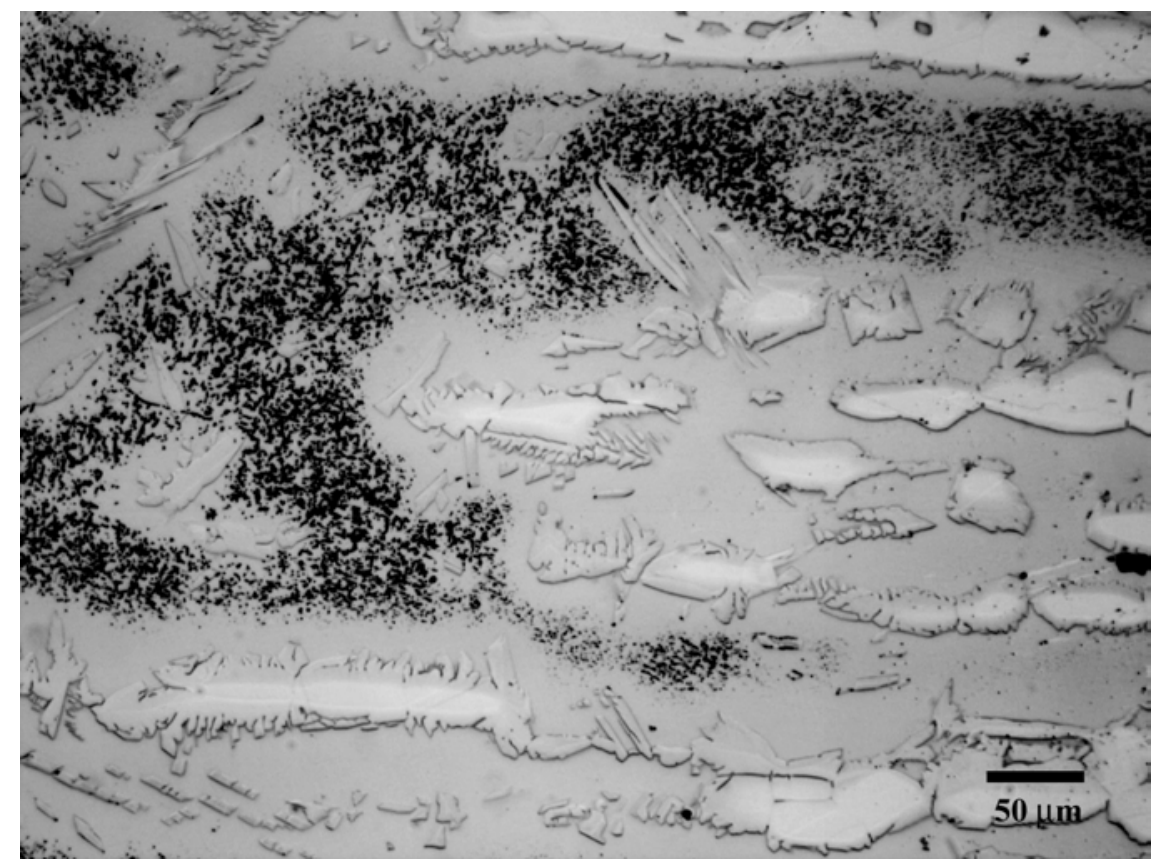

(b)

Figure 13(a\&b). Micrographs taken at higher magnifications in the spot weld HAZ in the vicinity of (a) Location A and (b) Location B, showing differences in the observed morphology of the austenite grains. 